\title{
OPEN Camel whey protein hydrolysates induced G2/M cellcycle arrest in human colorectal carcinoma
}

\author{
Chandraprabha Murali ${ }^{1}$, Priti Mudgil ${ }^{2}$, Chee-Yuen Gan ${ }^{3}$, Hamadeh Tarazi ${ }^{4}$, Raafat El-Awady ${ }^{4}$, \\ Youssef Abdalla ${ }^{5}$, Amr Amin ${ }^{1 凶}$ \& Sajid Maqsood ${ }^{2 \bowtie}$
}

Camel milk has been gaining immmense importance due to high nutritious value and medicinal properties. Peptides from milk proteins is gaining popularity in various therapeutics including human cancer. The study was aimed to investigate the anti-cancerous and anti-inflammatory properties of camel whey protein hydrolysates (CWPHs). CWPHs were generated at three temperatures $\left(30{ }^{\circ} \mathrm{C}\right.$, $37{ }^{\circ} \mathrm{C}$, and $\left.45^{\circ} \mathrm{C}\right)$, two hydrolysis timepoints (120 and $360 \mathrm{~min}$ ) and with three different enzyme concentrations $(0.5,1$ and $2 \%$ ). CWPHs demonstrated an increase in anti-inflammatory effect between 732.50 (P-6.1) and 3779.16 (P-2.1) $\mu \mathrm{g}$ Dicolfenac Sodium Equivalent (DSE)/mg protein. CWPHs (P-4.3 \& 5.2) inhibited growth of human colon carcinoma cells (HCT116) with an IC 50 value of 231 and $221 \mu \mathrm{g} / \mathrm{ml}$, respectively. P-4.3 induced G2/M cell cycle arrest and modulated the expression of Cdk1, p-Cdk1, Cyclin B1, p-histone H3, p21 and p53. Docking of two peptides (AHLEOVLLR and ALPNIDPPTVER) from CWPHs (P-4.3) identified Polo like kinase 1 as a potential target, which strongly supports our in vitro data and provides an encouraging insight into developing a novel peptide-based anticancer formulation. These results suggest that the active component, CWPHs (P-4.3), can be further studied and modeled to form a small molecule anti-cancerous therapy.

The rapid development in the field of proteomics has portrayed the evolution of proteins from being a mere nutritional component to a major contributor to the modulation of body's physiological functions. Food derived proteins render health benefits via the release of bioactive peptides upon gastrointestinal transformation mediated by hydrolysis induced by digestive enzymes, microbial proteases and fermentation ${ }^{1}$. Food derived peptides with anticancer and anti-inflammatory activities have been reported in a variety of food protein sources including milk, egg, fish, rice, soybean, pea and many others ${ }^{2}$. Bioactive peptides have been reported to regulate factors in carcinogenesis; oxidative stress and inflammation ${ }^{3}$. Therefore, their application in formulation of potential drugs, nutraceutical supplements and other pharmaceutical products has been widely investigated.

Bioactive peptides are highly selective to cancer cells and low toxicity to normal cells. Given their low molecular weight $\left(\sim 10^{2}-10^{3} \mathrm{Da}\right)$, they allow easy intercellular transportation and membrane interaction causing eventual cell death ${ }^{4}$. Anticancer peptides from marine life forms, reptiles, mammals and amphibians are studied ${ }^{5}$.

Due to its immense health benefits, camel milk has been receiving increasing global attention as one of the superfoods ${ }^{6}$. In the traditional medicine, local healers have claimed a therapeutic potential of a mixture of camel milk and urine to treat different types of cancer ${ }^{7}$. Unlike its bovine counterpart, camel milk is known to possess higher content of lactoferrin. Camel milk derived lactoferrin has been shown in vitro as a potent anticancer agent against colon cancer and breast cancer ${ }^{8}$. No detailed studies have been conducted to explore the anti-cancer effects of camel milk derived peptides. Our previous study reported potential anti-cancer capacity of camel whey protein hydrolysates against liver cancer in vitro ${ }^{9}$. Determination of anti-inflammatory and/or antioxidant properties has been proposed as a good indicator for screening anti-cancer agents ${ }^{10}$. With the ongoing advancement in the field of proteomics and bioinformatics, screening for novel anticancer peptides could emerge as a promising strategy to treat and/or prevent different types of cancers in the future. In this study we investigated the anti-proliferative property of the selected pepsin derived camel whey proteins hydrolysates on human cancer cells under in vitro conditions. Effects of hydrolysis variables such as E:S ratio, temperature, and reaction time

\footnotetext{
${ }^{1}$ Biology Department, College of Science, United Arab Emirates University, P.O. Box 15551, Al Ain, UAE. ${ }^{2}$ Food, Nutrition and Health Department, College of Food and Agriculture, United Arab Emirates University, P.O. Box 15551, Al Ain, UAE. ${ }^{3}$ Analytical Biochemistry Research Centre ( $\left.\mathrm{ABrC}\right)$, University Innovation Incubator Building, sains@ usm campus, Universiti Sains Malaysia, 11900 Bayan Lepas, Penang, Malaysia. ${ }^{4}$ College of Pharmacy, University of Sharjah, Sharjah, UAE. ${ }^{5}$ Department of Kinesiology, Michigan State University, East Lansing, MI 48824, USA. ${ }^{\circledR}$ email:a.amin@uaeu.ac.ae; sajid.m@uaeu.ac.ae
} 


\begin{tabular}{|c|c|c|c|c|c|}
\hline \multirow[b]{2}{*}{ CWPHs } & \multicolumn{3}{|c|}{ Hydrolysis parameters } & \multirow[b]{2}{*}{ DH (\%) } & \multirow[b]{2}{*}{ Anti-inflammatory activity (DSE $\mu \mathrm{g} / \mathrm{mg}$ PE) } \\
\hline & $\operatorname{Temp}\left({ }^{\circ} \mathrm{C}\right)$ & $\mathrm{E}(\%)$ & Time (h) & & \\
\hline Whey & 37 & 0 & 6 & & $435.83 \pm 46.45^{\mathrm{a}}$ \\
\hline P-1.1 & 30 & 2 & 2 & $43.22 \pm 0.65^{\mathrm{fg}}$ & $3628.33 \pm 168.78^{\mathrm{jk}}$ \\
\hline P-1.2 & 37 & 2 & 2 & $16.67 \pm 4.35^{\mathrm{ab}}$ & $1909.83 \pm 102.60^{\text {bcd }}$ \\
\hline P-1.3 & 45 & 2 & 2 & $14.67 \pm 2.24^{\mathrm{a}}$ & $1712.50 \pm 57.66^{\mathrm{b}}$ \\
\hline P-2.1 & 30 & 2 & 6 & $34.98 \pm 4.01^{\mathrm{e}}$ & $732.50 \pm 0.01^{\mathrm{a}}$ \\
\hline P-2.2 & 37 & 2 & 6 & $25.88 \pm 0.89^{c}$ & $2912.50 \pm 13.22^{\mathrm{i}}$ \\
\hline P-2.3 & 45 & 2 & 6 & $36.36 \pm 2.69^{\mathrm{ef}}$ & $1872.50 \pm 10.00^{\mathrm{bcd}}$ \\
\hline P-3.1 & 30 & 1 & 2 & $26.77 \pm 0.67^{\mathrm{c}}$ & $2894.83 \pm 32.97^{\mathrm{hi}}$ \\
\hline P-3.2 & 37 & 1 & 2 & $37.09 \pm 0.29^{\mathrm{ef}}$ & $2605.00 \pm 52.5^{\mathrm{gh}}$ \\
\hline P-3.3 & 45 & 1 & 2 & $26.06 \pm 1.26^{\mathrm{c}}$ & $2305.00 \pm 46.70^{\mathrm{ef}}$ \\
\hline P-4.1 & 30 & 1 & 6 & $52.38 \pm 1.06^{\mathrm{hi}}$ & $2537.50 \pm 15.00^{\mathrm{fg}}$ \\
\hline P-4.2 & 37 & 1 & 6 & $48.33 \pm 3.43^{h}$ & $1780.00 \pm 97.50^{\mathrm{bc}}$ \\
\hline P-4.3 & 45 & 1 & 6 & $23.47 \pm 0.85^{\mathrm{bc}}$ & $2072.50 \pm 90.00^{\text {cde }}$ \\
\hline P-5.1 & 30 & 0.5 & 2 & $27.80 \pm 0.25^{\mathrm{cd}}$ & $2657.50 \pm 250.00^{\mathrm{ghi}}$ \\
\hline P-5.2 & 37 & 0.5 & 2 & $23.85 \pm 1.64^{\mathrm{c}}$ & $1767.50 \pm 65.00^{\mathrm{b}}$ \\
\hline P-5.3 & 45 & 0.5 & 2 & $57.99 \pm 4.25^{\mathrm{i}}$ & $3415.00 \pm 122.50^{j}$ \\
\hline P-6.1 & 30 & 0.5 & 6 & $34.60 \pm 2.56^{\mathrm{de}}$ & $3779.16 \pm 42.52^{k}$ \\
\hline P-6.2 & 37 & 0.5 & 6 & $25.16 \pm 1.33^{c}$ & $2154.16 \pm 70.23^{\mathrm{de}}$ \\
\hline P-6.3 & 45 & 0.5 & 6 & $45.11 \pm 6.16^{\mathrm{gh}}$ & $1848.33 \pm 145.39^{\mathrm{bc}}$ \\
\hline
\end{tabular}

Table 1. Effect of hydrolysis parameters on the degree of hydrolysis (DH \%) and anti-inflammatory properties of peptic hydrolysates of camel whey proteins. Values represent mean \pm standard deviations of three $(n=3)$ measurements. For increase in $\mathrm{DH}(\%)$, values with different alphabets throughout the column are significantly $(\mathrm{p}<0.05)$ different and for anti-inflammatory activity, values in a column within enzyme concentration $(\%)$ are significantly $(\mathrm{p}<0.05)$ different. DSE: diclofenac sodium equivalent, $P E$ : protein equivalent.

were taken into consideration. Further potent hydrolysates underwent peptide sequencing followed by target protein binding studies to unravel the molecular mechanism.

\section{Results and discussion}

Effect of pepsin on the degree of hydrolysis (\% DH) under different conditions including the $\mathrm{E}: S$ ratio, time and temperature. Analysing the release of free amino nitrogen (F-AN) during the proteolysis provide an overall extent of protein hydrolysis in comparison to the intact protein sample. In order to achieve required level of hydrolysis, the enzyme:substrate ratio, time and temperature of hydrolysis are among the main variables that need to be taken into consideration while producing the protein hydrolysates. $\mathrm{DH}(\%)$ values of CWPHs are presented in Table 1. Overall, it was observed that DH values mainly increased with incubation time while no major effect of the enzyme concentration on $\% \mathrm{DH}$ was evident. Similarly, no direct correlation between temperature and $\mathrm{DH}$ values were observed. For hydrolysates produced at $2 \%$ enzyme concentration, maximum DH value was expressed by hydrolysates $\mathrm{P}-1.1$ produced at $30^{\circ} \mathrm{C}$ for $2 \mathrm{~h}$ of hydrolysis. While for hydrolysates produced at $1 \%$ enzyme concentration, the highest $\mathrm{DH}$ was observed at $37{ }^{\circ} \mathrm{C}$ and for $0.5 \%$ enzyme concentration, the highest $\mathrm{DH}$ was found at $45^{\circ} \mathrm{C}$. Overall, the hydrolysate P-5.3 and P-4.1 displayed a higher yield of hydrolysis with DH values of $\sim 57 \%$ and $52 \%$, respectively, which was achieved after $2 \mathrm{~h}$ and $6 \mathrm{~h}$ of hydrolysis time and 0.5 and $1.0 \%$ enzyme concentration, respectively. The increase in degree of hydrolysis with time of hydrolysis might be attributed to higher availability of cleavage sites upon denaturation of the native proteins leading to higher reactivity of enzymes and consequently the breakdown of more peptide bonds ${ }^{11}$. The results obtained are in agreement with earlier investigation where $\mathrm{DH}$ values of hydrolysates generated from camel whey proteins using gastrointestinal enzyme at $37^{\circ} \mathrm{C}$ was similar to the one reported here ${ }^{12}$. Studies related to the impact of pepsin digestion under variable conditions on the extent of hydrolysis of camel whey proteins are rather limited. However, a DH value of $20.5 \%$ has been reported upon peptic digestion of whole camel milk proteins for $30 \mathrm{~min}^{13}$. Those results were relatively higher than that observed by Salami, et al. ${ }^{14}$, where, hydrolysis of a-lactalbumin, a major whey protein, revealed a maximum $\mathrm{DH}$ value of $\sim 10 \%$ at $37{ }^{\circ} \mathrm{C}$ for $180 \mathrm{~min}$. These variations could simply be a result of using different camel milk protein matrix, as the whey used in the current study consisted of all major whey proteins like a-lactalbumin, serum albumins, lactoferrins and other minor whey proteins. That may explain the higher DH obtained in the present study.

Peptide profiles of intact camel whey proteins and their peptic hydrolysates. Reverse phaseultra performance liquid chromatography (RP-UPLC) was used for the characterization of intact CWP and its peptic hydrolysates. The results obtained are presented in Fig. 1a. It was revealed that for intact CWP, a single sharp peak belonging to $a$-lactalbumin (LA) was observed between 80 and $85 \mathrm{~min}$. Within the retention time ranging between $70-80 \mathrm{~min}$, other eluted peaks mostly representing other minor whey proteins such as serum 
(a)

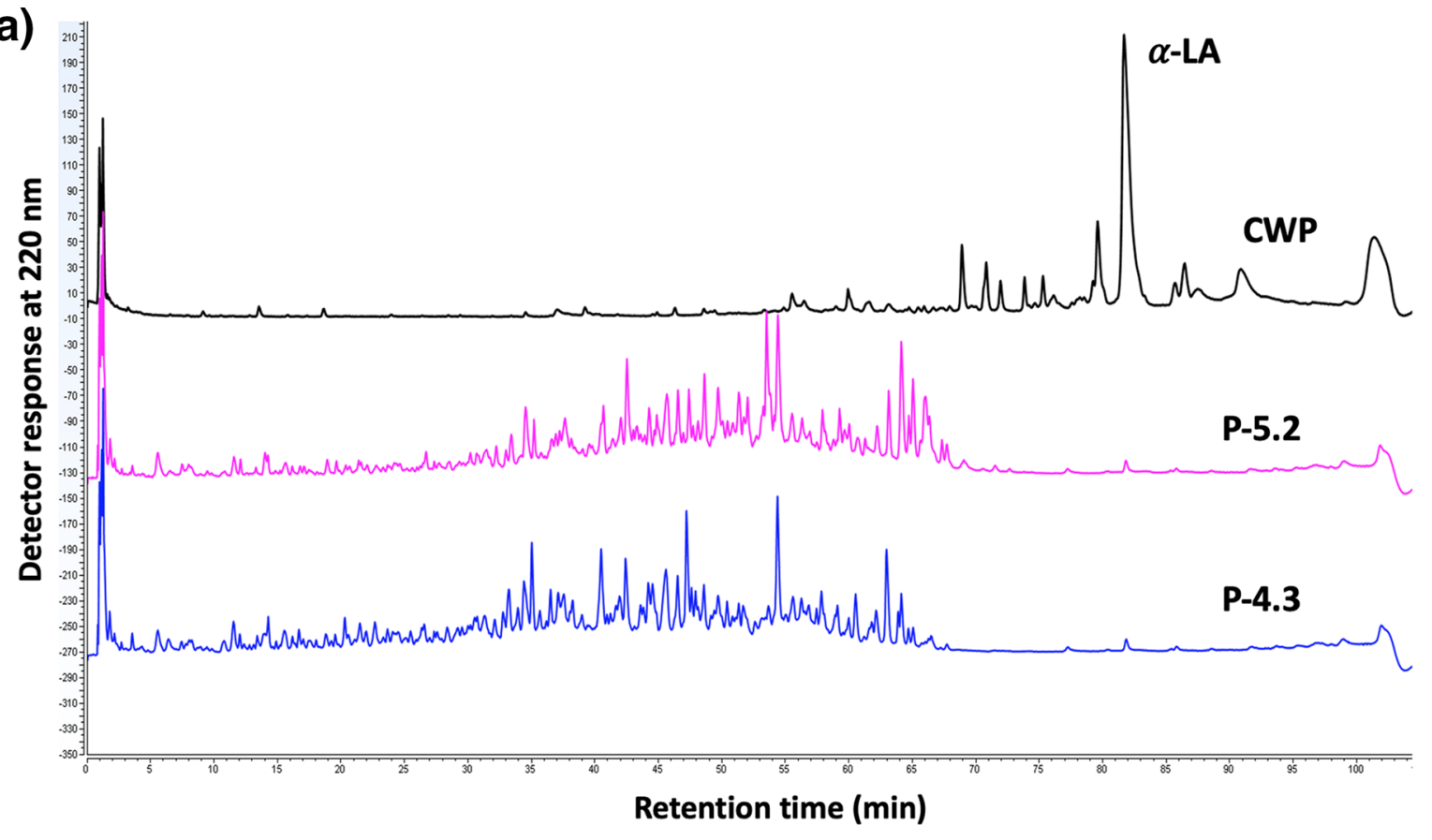

(b)
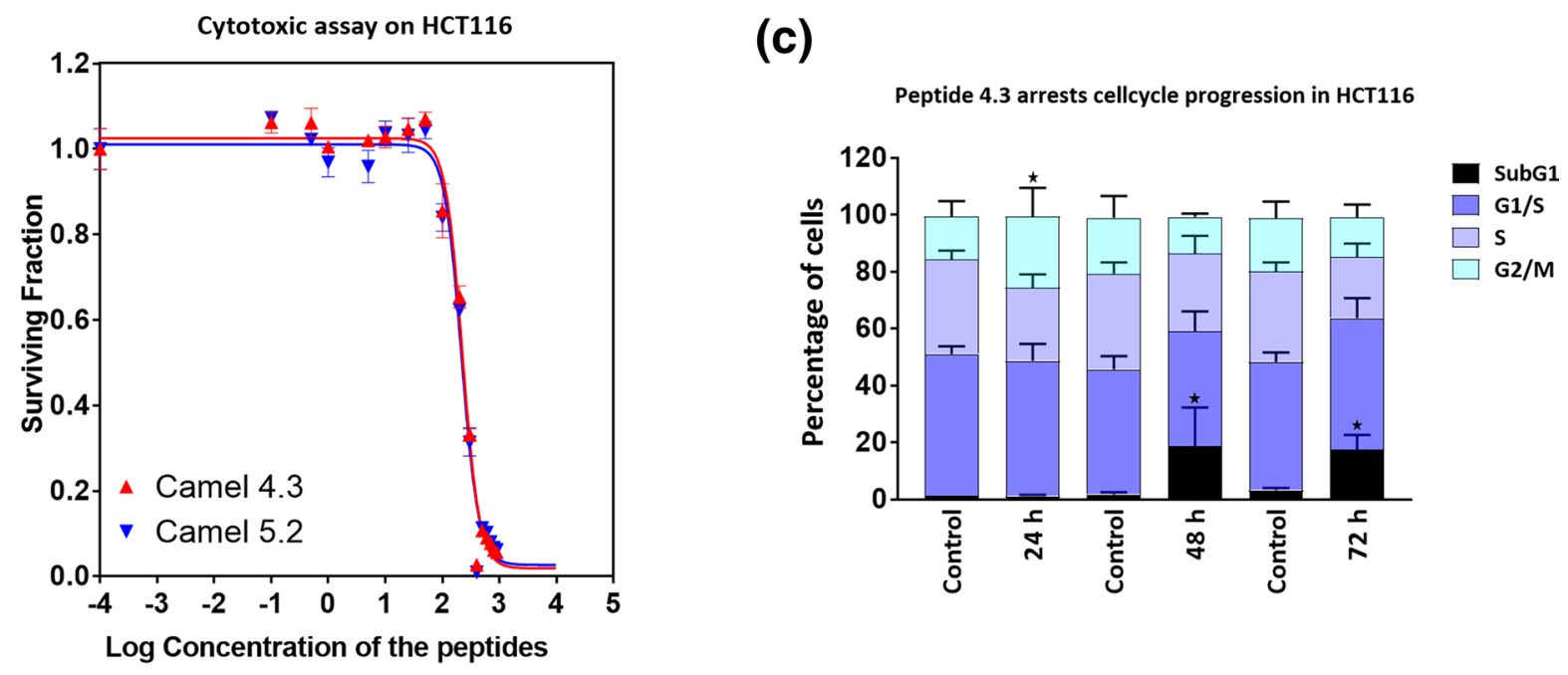

\begin{tabular}{|l|l|}
\hline Peptide & $\begin{array}{l}\text { IC50 } \\
(\mu \mathrm{g} / \mathrm{ml})\end{array}$ \\
\hline CWPH P-4.3 & 231 \\
\hline CWPH P-5.2 & 221 \\
\hline
\end{tabular}

Figure 1. Peptide profiling and anti-proliferative screening of camel whey protein hydrolysates (P-4.3 and P-5.2). (a) RP-UPLC peptide profile of CWP and their pepsin generated hydrolysates P-5.2 and P-4.3. (b) Camel whey protein hydrolysates P-4.3 and P-5.2 inhibit growth of HCT116 cells. Viability of HCT116 cells after treatment with increasing concentrations of the CWPHs P-4.3 and P-5.2 for a period of $48 \mathrm{~h} .231 \mu \mathrm{g} / \mathrm{ml}$ is the $\mathrm{IC}_{50}$ for CWPH P-4.3, $221 \mu \mathrm{g} / \mathrm{ml}$ is the $\mathrm{IC}_{50}$ for CWPH P-5.2. (c) Quantitative distribution of HCT116 cells in different phases of the cell cycle after treatment with camel CWPH P-4.3 $(231 \mu \mathrm{g} / \mathrm{ml})$ over a period of $24 \mathrm{~h}, 48 \mathrm{~h}$ and $72 \mathrm{~h}$. Statistical analysis was carried out by student's t-test using GraphPad Prism software and $\mathrm{p}<0.05$ was considered as statistically significant. ${ }^{*} \mathrm{p}<0.05,{ }^{* *} \mathrm{p}<0.01,{ }^{* *} \mathrm{p}<0.001$ and ${ }^{* * *} \mathrm{p}<0.0001$.

globulins, lactoferrin, immunoglobulin, lactoperoxidase were observed. Pepsin hydrolysis led to complete degradation of all the intact whey proteins as indicated by the peptide profile (Fig. 1a). The results are consistent with previous findings where simulated gastrointestinal digestion of camel whey protein concentrates treated with pepsin, trypsin and chymotrypsin resulted in complete hydrolysis of camel whey proteins ${ }^{1}$. The results indicate that camel whey protein hydrolysates contain a significant proportion of medium size peptides span- 
ning over a wide range of hydrophobicity and eluted between 35 and $70 \mathrm{~min}$. Smaller peaks of shorter peptides were also observed between the retention time 0-30 min. Previous studies have also reported that different camel milk protein hydrolysates generated with trypsin displayed short peptide peaks which were eluted over a range of retention time, indicating that camel milk protein hydrolysates contained peptides having a wide range of hydrophobicity ${ }^{15}$.

Effects of hydrolysis parameters (E:S, time and temperature) on anti-inflammatory activities. Inflammation is one of the most valuable mechanisms for defence or life-threatening side effects in our body. However, secretion of enormous amounts of inflammatory mediators including prostaglandin-E2 (PGE2), nitric oxide (NO), and pro-inflammatory cytokines such as IL-1 $\beta$, TNF- $\alpha$ and IL- 6 t has been associated with diseases like obesity, diabetes and cancer. The search for anti-inflammatory food-based bioactive compounds has shown that milk and its derived bioactive peptides can potentially be used as potent anti-inflammatory food derived bioactive compounds ${ }^{16}$. The anti-inflammatory activities of CWPHs are presented as equivalent to a standard anti-inflammatory drug diclofenac sodium per mg of protein equivalent [DSE ( $\mu \mathrm{g} / \mathrm{mg}$ PE)] in Table 1. Results suggest that the intact camel whey proteins displayed inherent anti-inflammatory capacity. Similar effect was reported in streptozotocin-induced diabetic rats supplemented with camel undenatured whey protein ${ }^{17}$. The hydrolysis of CWP with pepsin demonstrated a significant increase $(\mathrm{p}<0.05)$ in the anti-inflammatory effect of hydrolysates as compared to intact CWP (Table 1). Overall, the anti-inflammatory activity of 18 hydrolysates vary between 732.50 (P6.1) and 3779.16 (P2.1) $\mu \mathrm{g}$ DSE/mg PE. Some of the hydrolysates generated herein with camel whey exhibited activity higher than those reported earlier ${ }^{18}$, whereas others were comparable to those reported by Kamal et al. ${ }^{9}$. Previous studies have reported the role of milk derived bioactive peptides on the reduction of inflammation and an anti-inflammatory peptide "VPP" was identified ${ }^{19}$. Furthermore, alcalase and thermolysis driven hydrolysis of zein protein has been reported to produce three novel peptides PPYLSP, IIGGAL, and FLPPVTSMG with strong anti-inflammatory activities that regulate the expression of inflammation marker VCAM and ICAM ${ }^{20}$. The present study conclusively establishes the anti-inflammatory potential of camel whey protein derived hydrolysates and pave a way for further exploration to elucidate the molecular mechanism for anti-inflammatory properties of those hydrolysates.

Cytotoxicity of selected CWPHs against HCT116 cancer cells. Anti-proliferative effects of milk proteins have been studied earlier and are emerging as highly promising agents to overcome the relapse and side effects of chemotherapy ${ }^{21}$. Camel milk is known to induce growth arrest in breast cancer cells ${ }^{22}$ and trigger significant apoptosis effect in HepG2 cells ${ }^{23}$. 18 CWPHs were screened for anti-cancer activity on HepG2 cells (Supplementary Fig. S1) and two promising CWPHs P-4.3 and P-5.2 on HCT116 cells (Fig. 1b). HCT116 cells turned out to be a better model for studying the anti-oncogenic mechansism. The effect of CWPHs on the survival of HCT116 cells was investigated both at low $(0.01-10 \mu \mathrm{g} / \mathrm{ml})$ and high $(10-1000 \mu \mathrm{g} / \mathrm{ml})$ concentration ranges. Sigmoidal concentration-response curve fitting showed that the concentration needed to reduce the survival to $50 \%\left(\mathrm{IC}_{50}\right.$ ) for the CWPH P-4.3 and P5.2 was 231.0 and $221.0 \mu \mathrm{g} / \mathrm{ml}$, respectively.

Analysis of cell cycle distribution induced by CWPHs. Effect on cell cycle distribution by CWPH P-4.3 and P5.2 on HCT116 was investigated by FACS analysis. In cancer, therapeutic molecules disrupt the natural balance of cancer cells either by modulating cell cycle check points or eliciting unrepairable DNA damage and eventually promoting cell death. Earlier study where milk proteins induced cell cycle arrests ${ }^{24}$ encouraged us to investigate the molecular machinery of these hydrolysates. P-4.3 $(231 \mu \mathrm{g} / \mathrm{ml})$ showed a significant $(\mathrm{p}<0.05)$ $\mathrm{G} 2 / \mathrm{M}$ arrest when treated for $24 \mathrm{~h}(15-25 \%), 48 \mathrm{~h} \mathrm{(2-19 \% )}$ and $72 \mathrm{~h}(3-17 \%)$ (Fig. 1c). This could indicate that the P-4.3 induced apoptosis of the HCT116 cells or triggered non-cytotoxic growth arrest. P-5.2 $(221 \mu \mathrm{g} / \mathrm{ml}) \mathrm{did}$ not show any significant and consistent effect on the cell cycle progression of HCT116 cells. Hence, CWPH P-4.3 was further subjected to molecular analysis of its effector molecules.

Effect of CWPH P-4.3 on cell cycle variables. CWPH P-4.3-induced G2/M arrest in HCT116. The protein expression analyses of HCT116 with or without P-4.3 treated $(231 \mu \mathrm{g} / \mathrm{ml}$ at $24 \mathrm{~h}, 48 \mathrm{~h} \mathrm{\&} 72 \mathrm{~h})$ were done using western blot (Fig. 2). Cyclin dependent kinase 1(Cdk1) normally binds to Cyclin B1 to form a major regulator of mitosis. The synthesis and nuclear import of activated cyclin B1/Cdk1 complex peaks in late $S$ phase and early G2 phase. Inactivation of Cdk1 and proteolysis of Cyclin B1 halts cell division and promotes cells to exit mitosis. In the present study, CWPH P-4.3 decreased the expression of Cdk1 and cyclin B1 in a time-dependent manner (Fig. 2a,b) translating the G2/M arrest ${ }^{25}$. In cell cycle, each check points are tightly regulated to maintain the genomic integrity and cellular homeostasis. The inhibitory phosphorylation of Cdk1 at Tyr15 and Thr14 is a feedback mechanism that is known to regulate cell cycle. It is conjectured that the DNA damage occurred at G2 phase of cell cycle, sustains Cdk1 in a Thr14- and Tyr15-phosphorylated inactive state ${ }^{26}$. Here, there was a significant induction in the p-Cdk1(Tyr15) expression confirming the regulatory effect which resulted in cell cycle arrest (Fig. 2a,b). Phosphorylation of histone H3 Ser-10 (p-HH3) is known to take place when cells are treated with antiproliferative agents indicating DNA damage ${ }^{27}$. FACS illustrated a subG1 phase at 48 and $72 \mathrm{~h}$ post treatment (Fig. 1c) and that was significantly mirrored in the protein levels of p-HH3 (Fig. 2a,b) proving a DNA damage induced by the P- $4.3^{28}$.

We investigated the effect of p53/p21 cross talk post P-4.3 treatment. p53 is a tumour suppressor that acts as a dominant node in the cellular pathways responding to various events like DNA damage, oncogenic stimuli and chemical induced stress. Overexpression of p53 has been reported to induce both growth arrest and apoptosis ${ }^{29}$. The CDK inhibitor p21 (also known as p21WAF1/Cip1) acts as a negative regulator of p53-dependent apoptosis. P21 inactivates cyclinB1/Cdk1 complex leading to cell cycle arrest ${ }^{30}$. In this study, at $48 \mathrm{~h}$ following the 


\begin{tabular}{|c|c|c|c|c|c|c|c|}
\hline Peptide sequence & $\begin{array}{l}\text { Peptide ranker } \\
\text { score }\end{array}$ & \begin{tabular}{|l|} 
Mol \\
wt (g/ \\
mol)
\end{tabular} & Charge & Isoelectric point & Toxicity & AIP prediction & Anticp prediction \\
\hline \multicolumn{8}{|l|}{ P-4.3 } \\
\hline AHLEQVLLR & 0.83 & 1078.27 & 0.1 & 7.88 & Non-toxin & AIP & Anticp \\
\hline ALPNIDPPTVER & 0.82 & 1321.48 & -1 & 3.93 & Non-toxin & AIP & Anticp \\
\hline $\begin{array}{l}\text { AVLPFQEPVP- } \\
\text { DPVR }\end{array}$ & 0.75 & 1563.79 & -1 & 3.93 & Non-toxin & AIP & Anticp \\
\hline AVVSPIQF & 0.75 & 860.01 & 0 & 3.77 & Non-toxin & AIP & Anticp \\
\hline AVVSPIQFR & 0.75 & 1016.19 & 1 & 10.9 & Non-toxin & AIP & Anticp \\
\hline DDVVIK & 0.74 & \begin{tabular}{|l|}
687.78 \\
\end{tabular} & -1 & 3.71 & Non-toxin & AIP & Anticp \\
\hline DFLK & 0.74 & 521.61 & 0 & 6.66 & Non-toxin & AIP & Anticp \\
\hline DILK & 0.74 & 487.59 & 0 & 6.66 & Non-toxin & AIP & Anticp \\
\hline DILKEDMPSQR & 0.69 & 1331.5 & -1 & 4.17 & Non-toxin & AIP & Anticp \\
\hline DLENLHLPLPLL & 0.68 & 1386.63 & -1.9 & 3.92 & Non-toxin & AIP & Anticp \\
\hline DLENLHLPLPLLQ & 0.68 & 1514.76 & -1.9 & 3.92 & Non-toxin & AIP & Anticp \\
\hline DNENLQSR & 0.66 & 974.97 & -1 & 3.93 & Non-toxin & AIP & Anticp \\
\hline DSALGLLR & 0.65 & 843.97 & 0 & 6.68 & Non-toxin & AIP & Anticp \\
\hline DV & 0.65 & 232.23 & -1 & 0.72 & Non-toxin & AIP & Anticp \\
\hline DVQPTLSPGDR & 0.63 & 1184.26 & -1 & 3.71 & Non-toxin & AIP & Anticp \\
\hline DVTVLDNTDGK & 0.62 & 1176.23 & -2 & 3.41 & Non-toxin & Non-AIP & Anticp \\
\hline EDLVSK & 0.62 & 689.75 & -1 & 3.93 & Non-toxin & AIP & Anticp \\
\hline EDLVSKDDVVIK & 0.61 & 1359.52 & -2 & 3.82 & Non-toxin & AIP & Anticp \\
\hline EDLVSKDDVVIKS & 0.6 & 1446.6 & -2 & 3.82 & Non-toxin & AIP & Anticp \\
\hline ELAVVSPIQFR & 0.59 & 1258.47 & 0 & 6.86 & Non-toxin & AIP & Anticp \\
\hline ELTPGAATTLEGK & 0.59 & 1287.42 & -1 & 4.15 & Non-toxin & AIP & Anticp \\
\hline ENIDELKDTR & 0.58 & 1232.3 & -2 & 3.93 & Non-toxin & AIP & Anticp \\
\hline ENLHLPLPLL & 0.58 & 1158.39 & -0.9 & 5.1 & Non-toxin & AIP & Anticp \\
\hline ENLHLPLPLLQ & 0.58 & 1286.52 & -0.9 & 5.1 & Non-toxin & AIP & Anticp \\
\hline EPIPYPILP & 0.58 & 1038.24 & -1 & 1.1 & Non-toxin & AIP & Anticp \\
\hline EPVPDPVR & 0.57 & 908.01 & -1 & 3.93 & Non-toxin & AIP & Anticp \\
\hline EPVPDPVRG & 0.57 & 965.06 & -1 & 3.93 & Non-toxin & AIP & Anticp \\
\hline ETAAEVELR & 0.56 & \begin{tabular}{|l|}
1017.09 \\
\end{tabular} & -2 & 3.85 & Non-toxin & AIP & Anticp \\
\hline ETIIPK & 0.56 & 699.84 & 0 & 6.85 & Non-toxin & AIP & Anticp \\
\hline ETMDFLK & 0.55 & 883.02 & -1 & 3.93 & Non-toxin & AIP & Anticp \\
\hline $\mathrm{FE}$ & 0.54 & 294.3 & -1 & $\mathrm{pH} 1$ & Non-toxin & AIP & Anticp \\
\hline FLDDDLTDDK & 0.54 & 1196.22 & -4 & 3.11 & Non-toxin & AIP & Anticp \\
\hline FLPPLQPAV & 0.53 & 981.19 & 0 & 3.41 & Non-toxin & AIP & Anticp \\
\hline FLPPLQPAVM & 0.52 & 1112.39 & 0 & 3.46 & Non-toxin & AIP & Anticp \\
\hline FPHASEVVKPQ & 0.52 & 1238.39 & 0.1 & 7.56 & Non-toxin & AIP & Anticp \\
\hline FQEPVPDPVR & 0.52 & 1183.31 & -1 & 3.93 & Non-toxin & AIP & Anticp \\
\hline FRQENIDELK & 0.51 & 1291.41 & -1 & 4.32 & Non-toxin & AIP & Anticp \\
\hline FRQENIDELKDTR & 0.51 & 1663.79 & -1 & 4.44 & Non-toxin & AIP & Anticp \\
\hline GAHAGPTWNPISI & 0.51 & 1320.45 & 0.1 & 7.81 & Non-toxin & AIP & Anticp \\
\hline \begin{tabular}{l|l} 
GLFQ \\
\end{tabular} & 0.51 & 463.53 & 0 & 3.7 & Non-toxin & AIP & Non-Anticp \\
\hline GLHPVPQP & 0.5 & 843.97 & 0.1 & 7.81 & Non-toxin & AIP & Non-Anticp \\
\hline GLHPVPQPLV & 0.5 & 1056.26 & 0.1 & 7.81 & Non-toxin & AIP & Non-Anticp \\
\hline \multicolumn{8}{|l|}{ P-5.2 } \\
\hline LRPFL & 0.93 & 644.81 & 1 & 0.84 & Non-toxin & AIP & Anticp \\
\hline LRFPL & 0.91 & 644.81 & 1 & 0.84 & Non-toxin & AIP & Anticp \\
\hline LC & 0.84 & 234.32 & -0.1 & 3.11 & Non-toxin & AIP & Anticp \\
\hline HSGF & 0.81 & 446.46 & 0.1 & 7.56 & Non-toxin & AIP & Anticp \\
\hline LWKL & 0.79 & 558.71 & 1 & 0.12 & Non-toxin & AIP & Anticp \\
\hline PLLL & 0.74 & 454.6 & 0 & 4.08 & Non-toxin & AIP & Anticp \\
\hline $\begin{array}{l}\text { ESLPGVPPPSGQ- } \\
\text { PLL }\end{array}$ & 0.74 & 1487.7 & -1 & 0.92 & Non-toxin & Non-AIP & Anticp \\
\hline KPVMECGALLL & 0.7 & 1173.49 & -0.1 & 6.12 & Non-toxin & AIP & Anticp \\
\hline CHLL & 0.68 & 484.62 & 0 & 7.09 & Non-toxin & AIP & Anticp \\
\hline CFNTLMLPPEPLL & 0.67 & 1487.83 & -1.1 & 0.92 & Non-toxin & AIP & Anticp \\
\hline
\end{tabular}




\begin{tabular}{|l|l|l|l|l|l|l|l|}
\hline Peptide sequence & $\begin{array}{l}\text { Peptide ranker } \\
\text { score }\end{array}$ & $\begin{array}{l}\text { Mol } \\
\mathbf{w t}(\mathbf{g} / \\
\mathbf{m o l})\end{array}$ & Charge & Isoelectric point & Toxicity & AIP prediction & Anticp prediction \\
\hline SHGM & 0.66 & 430.48 & 0.1 & 7.54 & Non-toxin & AIP & Anticp \\
\hline QVNLPLTGGML & 0.64 & 1142.37 & 0 & 3.34 & Non-toxin & AIP & Anticp \\
\hline HSYAEEPPLYPLL & 0.63 & 1528.7 & -1.9 & 4.14 & Non-toxin & AIP & Anticp \\
\hline DLPLMT & 0.6 & 688.84 & -1 & 0.75 & Non-toxin & Non-AIP & Anticp \\
\hline NNLPLTM & 0.58 & 801.95 & 0 & 3.29 & Non-toxin & AIP & Anticp \\
\hline PLMLPLHQPL & 0.57 & 1158.46 & 0.1 & 8.26 & Non-toxin & AIP & Anticp \\
\hline DLLPLTM & 0.57 & 801.99 & -1 & 0.78 & Non-toxin & AIP & Anticp \\
\hline FLEL & 0.55 & 520.62 & -1 & 0.92 & Non-toxin & AIP & Anticp \\
\hline NHCDEPVPMT & 0.54 & 1142.27 & -2 & 3.92 & Non-toxin & AIP & Anticp \\
\hline
\end{tabular}

Table 2. In silico analysis of anti-inflammatory, anti-cancer and toxicity prediction of identified potential biologically active peptides from CWPHs P4.3 and 5.2 as revealed by their peptide ranker score, ToxinPred, Anticp and AIPpred. Anticp anti-cancer peptide, AIP anti-inflammatory peptide.

(a)

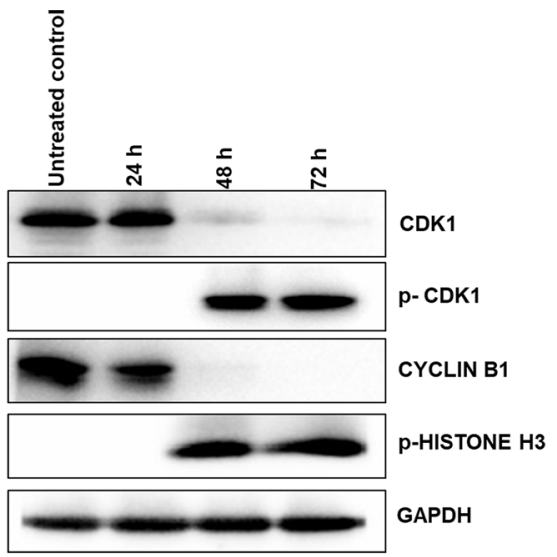

(c)
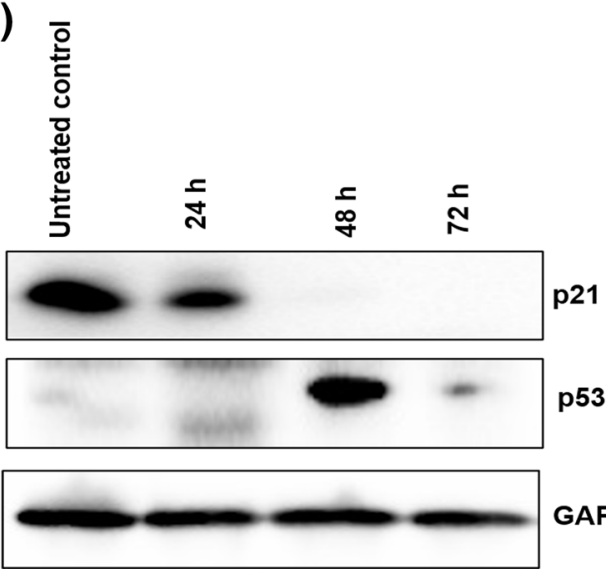

(b)

Densitometric analysis of western blot in HCT116 cells

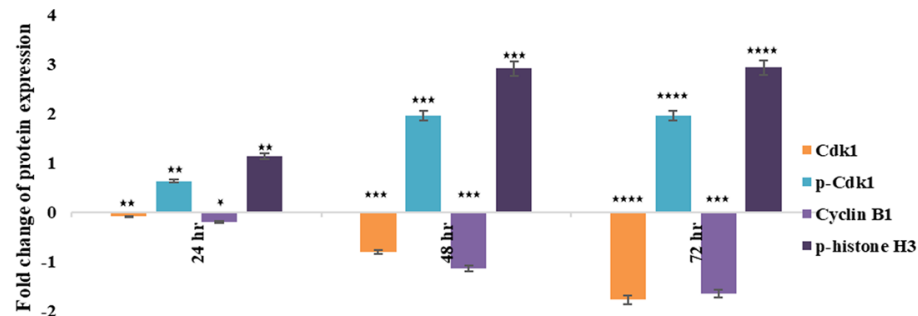

DURATION OF INCUBATION WITH PEPTIDE $4.3(231 \mu \mathrm{g} / \mathrm{mI})$

(d)

GAPDH

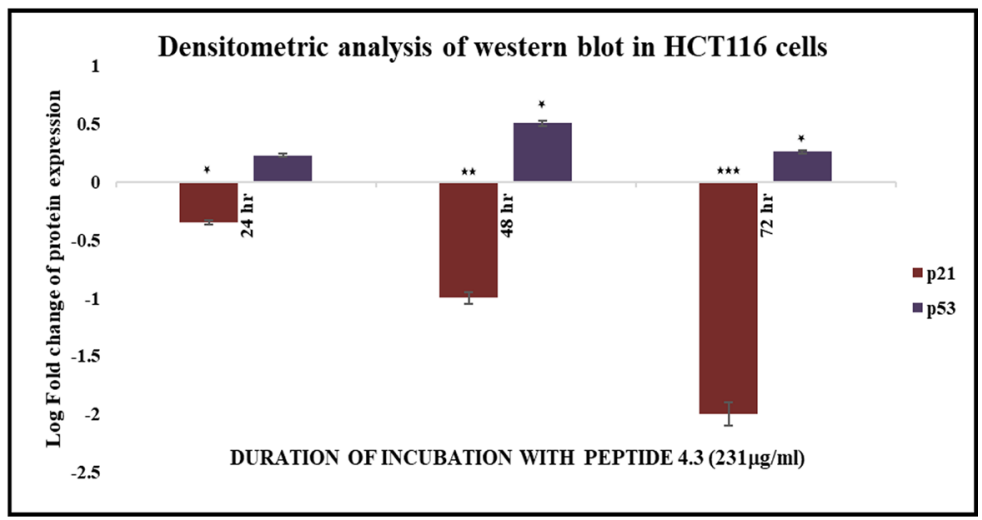

Figure 2. Inhibitory effect of CWPH P-4.3 on cell cycle progressive markers in HCT116 cells. (a, c) Western blot analysis of cell cycle regulatory proteins from HCT116 treated with CWPH P-4.3 $(231 \mu \mathrm{g} / \mathrm{ml})$ over a period of $24 \mathrm{~h}, 48 \mathrm{~h}$ and $72 \mathrm{~h}$. (b, d) Each band intensity was quantified to analyze the protein expression using ImageJ, normalized relative to their respective loading control bands. Values are expressed as ratio of untreated control in $\log$ fold. Statistical analysis was carried out by student's t-test using GraphPad Prism software and $\mathrm{p}<0.05$ was considered as statistically significant. ${ }^{\star} \mathrm{p}<0.05,{ }^{* *} \mathrm{p}<0.01,{ }^{\star * *} \mathrm{p}<0.001$ and ${ }^{\star * *} \mathrm{p}<0.0001$. 
CWPH P-4.3 treatment, an induction of p53 and a p21 inhibition were observed (Fig. 2c,d). Interruptions of tightly regulated pathways are classic properties of cancer cells backing the irregularity in the $\mathrm{p} 21 / \mathrm{p} 53$ pathway when exposed to our antiproliferative agent. Protein expression of $\mathrm{p} 21$ is at variance with that of $\mathrm{p} 53$ amongst the treated and untreated HCT116 cells. This may indicate a p53 independent mechanism by the CWPH. A variety of transcription factors have proven to regulate $\mathrm{p} 21$ independent of $\mathrm{p} 53$ and $\mathrm{p} 150^{\mathrm{Sal} 2}$, is an example ${ }^{31}$. This opens doors to more studies in order to understand the CWPH induced anti-cancer effect.

Identification and physicochemical properties of peptide. Based on their significant potential anticancer effect (Fig. 1b), CWPHs P-4.3 and P-5.2 were processed for peptide sequence identification and the interaction of selected peptides with target protein via in-silico analysis was also carried out. All results relevant to the number of peptides, their sequence, physicochemical properties and predictions related to their antiinflammatory and anti-cancer potential are presented in Table 2. Overall, 162 and 44 peptides were identified in CWPH P-4.3 and P-5.2, respectively (Supplementary material-Table S1). Depending on the average local confidence (ALC) value of at least $80 \%$ and on the peptide ranker score of $>0.50$, peptides were represented as potentially biologically active peptides (BAPs). A total of 42 and 19 peptides from P-4.3 and P-5.2, respectively were qualified (peptide ranker score of $>0.5$ ) to be BAPs (Table 2). The molecular weight of these BAPs varied from $234.32 \mathrm{~g} / \mathrm{mol}$ for LC (P-5.2) to $1563.79 \mathrm{~g} / \mathrm{mol}$ for AVLPFQEPVPDPVR (P-4.3). Isoelectric point values varied between $\mathrm{pH} 0.9$ and 10.9 among generated peptides. It has been previously reported that the anti-inflammatory action of proteins or their derived peptides is highly dependent on the sequence and structure of the peptides. Buffalo milk casein-derived decapeptide suppressed inflammatory cytokine levels, splenocytes proliferation and improved the phagocytosis in mice which are the classic anti-inflammatory indicators ${ }^{32}$. aS1-casein derived peptide has been shown to inhibit the matrix metalloproteinases (MMP-9) activity in HT-29 and SW480 cells s3 $^{33}$. Hence, anti-cancer peptide (ANTICP) and anti-inflammatory (AIP) web-based prediction servers, were used to determine the anticancer and anti-inflammatory peptides, respectively. They utilize support vector machine (SVM) models developed based on amino acid composition and binary profile features inorder to predict the activity of the peptides. All peptides except DVTVLDNTDGK (P-4.3), ESLPGVPPPSGQPLL and DLPLMT (P-5.2) were predicted to be anti-inflammatory (AIP). Toxicity impedes the inclusion of BAPs in the food and pharmaceutical industry. Therefore, resulted peptides were screened for their toxicity using ToxinPred and none of them turned out to be toxic. In addition, all peptides except GLFQ, GLHPVPQP and GLHPVPQPLV (P-4.3) were predicted to have anti-cancer potential.

Macromolecular target prediction. An in silico approach of molecular docking was done using two peptide sequences (AHLEQVLLR and ALPNIDPPTVER) derived from camel whey protein hydrolysate P-4.3 (score > 0.8 ) (Table 2), in an attempt to search for its most probable macromolecular protein targets. For this purpose, we initiated this by utilizing a number of web-based search engines. The first engine being utilized was the SwissTargetPrediction server, where it predicts bioactivity based on 2D/3D similarity search of $370 \mathrm{~K}$ active compounds spaning over $3 \mathrm{~K}$ macromolecular protein targets. Moreover, MolTarPred search engine was utilized to scan over $600 \mathrm{~K}$ active compounds and over $4.5 \mathrm{~K}$ macromolecular targets, while the PASS server was utilized to scan more than $260 \mathrm{~K}$ compounds with known biological activities employing a knowledge base-rules about their structure-activity relationships. On the other hand, cross-target similarity maps were predicted via the SEA (Similarity Ensemble Approach) search engine that produces its results based on chemical similarity and biological clustering. The results obtained from these web-based search engines were further filtered based on their top-ranked scores and oncogenic target involvement. Finally, the macromolecular targets involvement hypotheses were judged based on their initial biological screening (i.e., western-blot). Accordingly, a number of biological targets were nominated for the initial biological screening, nevertheless one target namely; PLK-1 Polo box domain was confirm and supported by the biological data.

The most probable binding modes for peptides within the Polo like kinase 1 (PLK1) were explored by performing molecular docking calculations and employing MDockPeP server. For peptide-1 (AHLEQVLLR), the model with the highest ITScorePeP (-160.441) was considered. Peptide-1 (AHLEQVLLR) demonstrated effective binding efficiency with the enzyme active site (Fig. 3a left) and was able to establish two hydrogen bond interactions with the corresponding Arg-516 and His-538 amino acid residues (Fig. 3a right). On the other hand, the binding mode of peptide-2 (ALPNIDPPTVER) was estimated to be more significant with a calculated ITScorePeP of -162.385 . The binding mode of Peptide- 2 was in agreement with that of peptide-1 (Fig. $3 \mathrm{~b}$ left), and peptide- 2 was able to establish three hydrogen bond interactions with the Tyr-417, Tyr-485 and Arg-516 active site residues (Fig. 3b right). A strong interactive profile was found among Polo-like kinase-1 (Plk1) with both the peptide1 and 2 (Fig. 3a,b).

These docking analysis results are consistent with our in vitro analysis where Plk1 expression is crucial for controlling G2/M phase of the cell cycle and is overexpressed in many tumour types. In pre-clinical studies, Plk1 inhibitors were showing significant upregulation in the expression of the mitotic marker p-Histone $\mathrm{H} 3$. PLK1 induced phosphorylation of cyclin B1 is necessary for the formation of Cdk1/Cyclin B1 complex which in turn initiates the mitotic entry of a cell ${ }^{34}$. There are two projected models demonstrating PBD mediated PLK1 kinase activity. Our data suggests a 'Processive phosphorylation' model keeping into account of the CDK1 phosphorykation ${ }^{35}$. Taken together, Plk1 seems to have a major role in inducing the anti-mitotic and proapoptotic effects imparted in vitro by the camel whey derived bioactive peptides.

In silico structural activity relationship (SAR) of identified peptides to Polo-Like Kinase $\mathbf{1}$ (PLK1). Active site interaction between PLK-1 (PDB code: 3RQ7) and bioactive peptides from CWPHs (P-4.3 and P-5.2) were studied using PepSite 2. Human protein Polo-Like Kinase 1 (PLK1) plays an important 
(a)

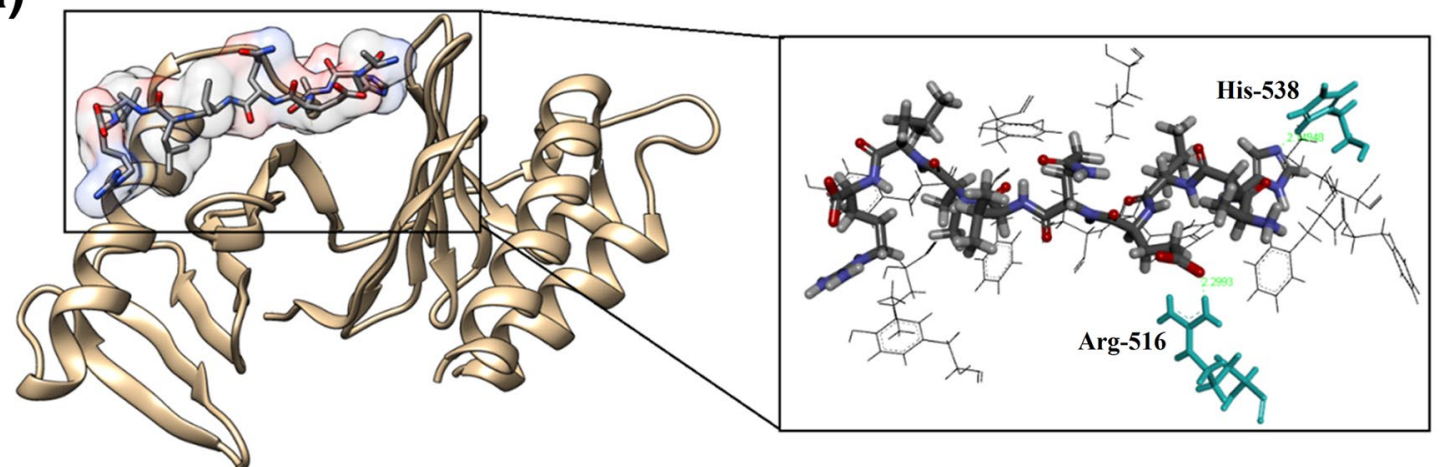

(b)

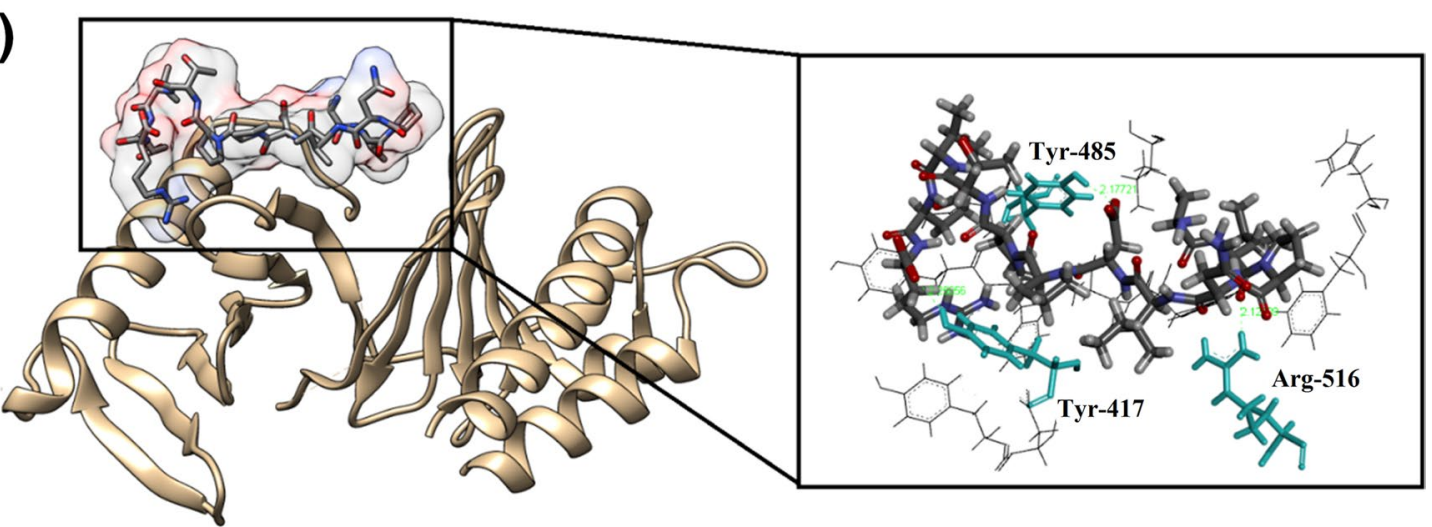

Figure 3. Investigated peptides binding modes within the active site of PLK-1 Polo box domain (PDB-ID: 3RQ7). (a) Binding mode of peptide-1 (AHLEQVLLR) from CWPHs P-4.3 within the active site of PLK-1, (b) Binding mode of peptide-2 (ALPNIDPPTVER) from CWPHs P-4.3 within the active site of PLK-1. Left panels illustrated the overall binding site, while the right panels illustrated hydrogen bond interactions with the residues of the active site. Ligands and important amino acids residues are presented in stick rendering, while $\mathrm{H}$-bond interactions are shown as green dashed lines with their corresponding distances in angstrom.

regulatory role in mitosis and cellular proliferation through phosphorylation of different substrates. PLK1 is found to be overexpressed in a variety of cancers like prostrate and colorectal cancers ${ }^{36}$. Therefore, potential inhibitors of this protein are sought after for developing novel anti-cancer drugs. Inhibiting the activity of PLK1 through phospho-ligand binding of the Polo Box Domain (PBD) is a potential cancer therapy as it might prevent the completion of the cell cycle and induce apoptosis. Therefore, an intriguing array of novel PLK1 inhibitors is being explored for their potential inhibitory activity against PLK1. The detailed structural analysis of PLK1 has revealed that the PBD is important for PLK1 activity. It was reported that Val415, Tyr417, Tyr421, Leu478, Tyr481, Phe482 and Tyr485 are recognised as the cryptic binding pockets on the PLK-1 PBD surface ${ }^{37}$. These residues regulate the substrate recognition by adopting open and closed conformations and by binding a peptide at these PBD surface residues, substrate discrimation could occur, thus inhibiting the overexpression of PLK1 in the tumor cells. Table 3 shows the $p$ value as a measure to binding strength, reactive residue in the peptides and the potential binding sites of the identified peptides with PLK-1. It was predicted that most of the peptides in P-4.3 and P-5.2 hydrolysates were capable of binding to 5-7 cryptic binding sites (CBS) of PLK1. These CBS binding sites essentially mirror the anticancer properties of CWPH P-4.3.

\section{Conclusion}

The anti-cancerous properties of the pepsin digested CWPH have been demonstrated in this study for the first time divulging two promising peptide sequences AHLEQVLLR and ALPNIDPPTVER with a potential of target therapy. G2/M cell cycle markers were affected by the CWPH P-4.3. Data of the in-silico study also identifies PLKI-1 as a potential target of the CWPH P-4.3 (Fig. 4). Future studies on potential peptides sequence in a purified form should be carried out to investigate the anticancer activity in in-vitro as well as in-vivo model systems and their pharmacokinetic aspects like absorption, distribution, and bioavailability within the cells should be studied. 


\begin{tabular}{|c|c|c|c|c|}
\hline Peptide & Pepsite-2 p-value & Reactive peptide residues & Bound sites (3RQ7) & CBS \\
\hline \multicolumn{5}{|l|}{ P-4.3 } \\
\hline AHLEQVLLR & 0.02195 & $\mathrm{~A} 1, \mathrm{H} 2, \mathrm{~L} 3, \mathrm{E} 4, \mathrm{Q} 5, \mathrm{~V} 6$ & Val415, Tyr417a, Tyr $481^{\mathrm{a}}$, Phe $482^{\mathrm{a}}$, Tyr $485^{\mathrm{a}}$, His 489 & 5 \\
\hline ALPNIDPPTVER & 0.001197 & A1, L2 P3, N4, I5, P7, P8, T9, V10, R12 & $\begin{array}{l}\text { Val415ª Tyr417 }{ }^{\mathrm{a}} \text {, Tyr } 421^{\mathrm{a}} \text {, Lys474, Leu } 478^{\mathrm{a}} \text {, Tyr } 481^{\mathrm{a}} \text {, Phe } 482^{\mathrm{a}} \text {, Tyr } 485^{\mathrm{a}} \text {, } \\
\text { His489 }\end{array}$ & 7 \\
\hline AVLPFQEPVPDPVR & 0.0008096 & $\mathrm{~A} 1, \mathrm{~V} 2, \mathrm{~L} 3, \mathrm{P} 4, \mathrm{~F} 5, \mathrm{Q} 6, \mathrm{P} 8, \mathrm{P} 10, \mathrm{D} 11, \mathrm{P} 12, \mathrm{~V} 13, \mathrm{R} 14$ & 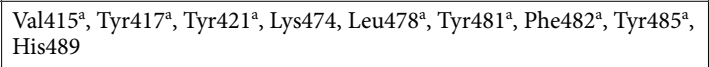 & 7 \\
\hline AVVSPIQF & 0.003612 & V2, S3, P5, I6, Q7, F8 & 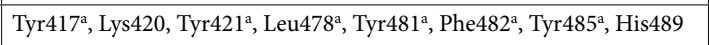 & 6 \\
\hline AVVSPIQFR & 0.004457 & V3, P5, I6, Q7, F8, R9 & Tyr417a, Lys420, Tyr421a, Lys474, Leu478, Tyr481a, Phe482a, Tyr485a & 6 \\
\hline DDVVIK & 0.01484 & D1, V3, V4, I5, K6 & 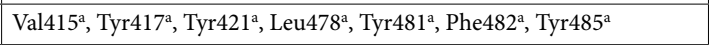 & 7 \\
\hline DFLK & 0.01728 & D1, F2, L3, K4 & 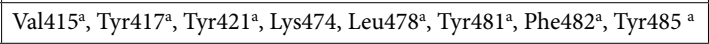 & 7 \\
\hline DILK & 0.01554 & D1, I2, L3, K4 & 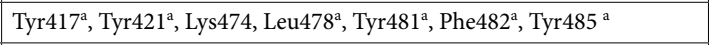 & 6 \\
\hline DILKEDMPSQR & 0.01104 & D1, I2, L3, K4, D6, M7, P8, Q10, R11 & 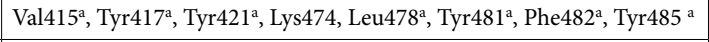 & 7 \\
\hline DLENLHLPLPLL & 0.01863 & D1, E3, N4, L5, H6, L7, P8, L9, P10, L12 & 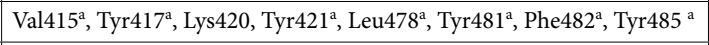 & 7 \\
\hline DLENLHLPLPLLQ & 0.01821 & D1, E3, N4, L5, H6, L7, P8, L9, P10, L12, Q13 & $\begin{array}{l}\text { Val415 }{ }^{\mathrm{a}} \text {, Tyr417 }{ }^{\mathrm{a}} \text {, Lys420, Tyr421 }{ }^{\mathrm{a}} \text {, Leu } 478^{\mathrm{a}} \text {, Tyr } 481^{\mathrm{a}} \text {, Phe } 482^{\mathrm{a}} \text {, Tyr } 485^{\mathrm{a}} \text {, } \\
\text { His } 489\end{array}$ & 7 \\
\hline DNENLQSR & 0.007954 & D1, N2, E3, N4, L5, Q6 & 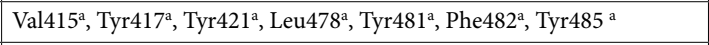 & 7 \\
\hline DSALGLLR & 0.01869 & S2, A3, L4, G5, L6, R7 & 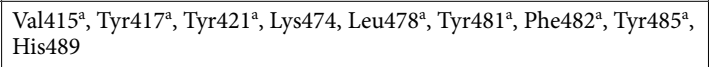 & 7 \\
\hline DV & 0.09958 & D1, V2 & Tyr417ª Leu $478^{\mathrm{a}}$, Tyr $481^{\mathrm{a}}$, Phe $482^{\mathrm{a}}$, Tyr $485^{\mathrm{a}}$ & 5 \\
\hline DVQPTLSPGDR & 0.006228 & V2, Q3, P4, T5, L6, P8, G9, D10, R11 & 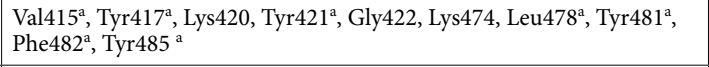 & 7 \\
\hline DVTVLDNTDGK & 0.02695 & D1, T3, V4, L5, D6, N7, T8, G10, K11 & 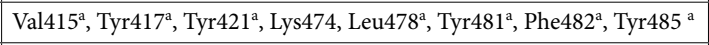 & 7 \\
\hline EDLVSK & 0.06053 & D2, L3, V4, S5, K6 & Tyr417ª, Tyr421 a Lys474, Leu478a, Tyr481ª, Phe $482^{a}$, Tyr485a , His489 & 6 \\
\hline EDLVSKDDVVIK & 0.03769 & D2, L3, V4, S5, K6, D7, V9, V10, I11, K12 & 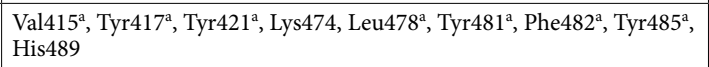 & 7 \\
\hline EDLVSKDDVVIKS & 0.03637 & D2, L3, V4, S5, K6, D7, D8, V9, V10, I11, K12 & 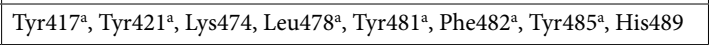 & 6 \\
\hline ELAVVSPIQFR & 0.01091 & L2, A3, V4, V5, S6, P7, I8, Q9, F10 & 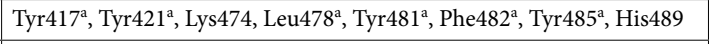 & 6 \\
\hline ELTPGAATTLEGK & 0.01091 & E1, L2, T3, P4, A6, A7, T8, T9, L10, E11, K13 & 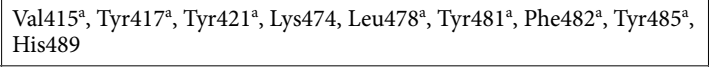 & 7 \\
\hline ENIDELKDTR & 0.04065 & N2, I3, L6, D8, T9, R10 & $\begin{array}{l}\text { Tyr } 417^{\mathrm{a}} \text {, Lys420, Tyr421 } 1^{\mathrm{a}} \text {, Lys474, Leu478a, Tyr481 }{ }^{\mathrm{a}} \text {, Phe } 482^{\mathrm{a}} \text {, Tyr } 485^{\mathrm{a}} \text {, } \\
\text { His489 }\end{array}$ & 6 \\
\hline ENLHLPLPLL & 0.004611 & H4, L5, P6, L7, P8, L10 & $\begin{array}{l}\text { Val415, , Tyr417a, Lys420, Tyr421 a , Lys474, Leu } 478^{\mathrm{a}} \text {, Tyr } 481^{\mathrm{a}} \text {, Phe } 482^{\mathrm{a}} \text {, } \\
\text { Tyr485a, His } 489\end{array}$ & 7 \\
\hline ENLHLPLPLLQ & 0.01709 & N2, L3, H4, L5, P6, L7, P8, L10, Q11 & 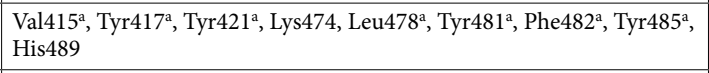 & 7 \\
\hline EPIPYPILP & 0.001003 & I3, P4, P6, I7, L8, P9 & 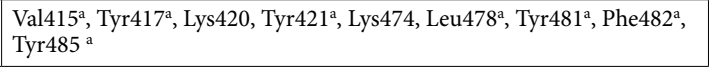 & 7 \\
\hline EPVPDPVR & 0.001355 & $\mathrm{P} 2, \mathrm{P} 4, \mathrm{D} 5, \mathrm{P} 6, \mathrm{~V} 7, \mathrm{R} 8$ & 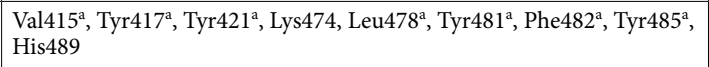 & 7 \\
\hline EPVPDPVRG & 0.001965 & $\mathrm{P} 2, \mathrm{P} 4, \mathrm{D} 5, \mathrm{P} 6, \mathrm{~V} 7, \mathrm{R} 8$ & 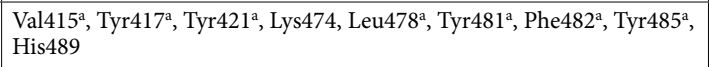 & 7 \\
\hline ETAAEVELR & 0.02771 & T2, A3, A4, V6, L8, R9 & 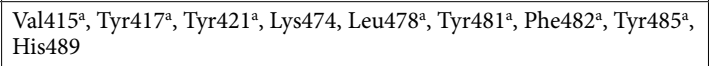 & 7 \\
\hline ETIIPK & 0.004608 & T2, I3, I4, P5, K6 & 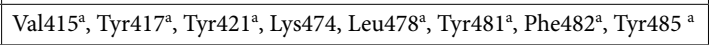 & 7 \\
\hline ETMDFLK & 0.007162 & T2, M3, D4, F5, L6, K7 & $\begin{array}{l}\text { Val415, Tyr417 }{ }^{\mathrm{a}} \text {, Tyr } 421^{\mathrm{a}} \text {, Lys } 474, \text { Leu } 478^{\mathrm{a}} \text {, Tyr } 481^{\mathrm{a}} \text {, Phe } 482^{\mathrm{a}} \text {, Tyr } 485^{\mathrm{a}} \text {, } \\
\text { His } 489\end{array}$ & 7 \\
\hline $\mathrm{FE}$ & 0.07216 & F1, E2 & Tyr $417^{\mathrm{a}}, \operatorname{Tyr} 421^{\mathrm{a}}$, Tyr $485^{\text {a }}$ & 3 \\
\hline FLDDDLTDDK & 0.04962 & D3, D4, L6, T7, D8, D9 & 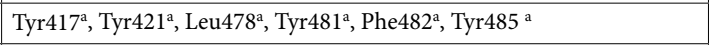 & 6 \\
\hline FLPPLQPAV & 0.0006121 & F1, P3, P4, L5, Q6, P7 & 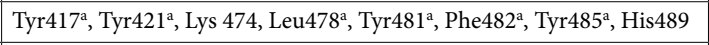 & 6 \\
\hline FLPPLQPAVM & 0.0008342 & F1, P3, P4, L5, Q6, P7 & Tyr417ª, Tyr421 a Lys 474, Leu $478^{\mathrm{a}}$, Tyr $481^{\mathrm{a}}$, Phe $482^{\mathrm{a}}$, Tyr $485^{\mathrm{a}}$, His 489 & 6 \\
\hline FPHASEVVKPQ & 0.00126 & $\mathrm{~F} 1, \mathrm{P} 2, \mathrm{H} 3, \mathrm{~A} 4, \mathrm{~S} 5, \mathrm{~V} 8, \mathrm{~K} 9, \mathrm{P} 10, \mathrm{Q} 11$ & 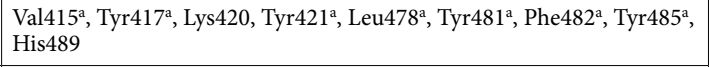 & 7 \\
\hline FQEPVPDPVR & 0.001478 & Q2, E3, P4, V5, P6, P8 & 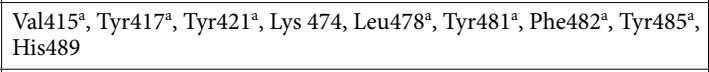 & 7 \\
\hline FRQENIDELK & 0.01164 & F1, R2, Q3, N5, I6, D7 & 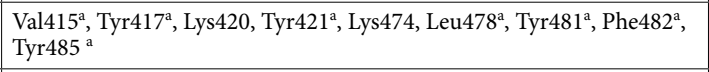 & 7 \\
\hline FRQENIDELKDTR & 0.0108 & F1, R2, Q3, N5, I6, D7, L9, K10, D11, T12, R13 & 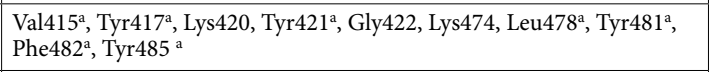 & 7 \\
\hline GAHAGPTWNPISI & 0.007397 & G1, H3, A4, P6, W8, N9, P10, I11, S12, I13 & $\begin{array}{l}\text { Val415ª, Tyr417 }{ }^{\mathrm{a}} \text {, Lys } 420, \text { Tyr } 421^{\mathrm{a}} \text {, Lys } 474, \text { Leu } 478^{\mathrm{a}} \text {, Tyr } 481^{\mathrm{a}} \text {, Phe } 482^{\mathrm{a}} \text {, } \\
\text { Tyr485, His } 489\end{array}$ & 7 \\
\hline GLFQ & 0.002078 & G1, L2, F3, Q4 & 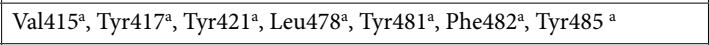 & 7 \\
\hline GLHPVPQP & 0.0002835 & H3, P4, V5, P6, Q7, P8 & 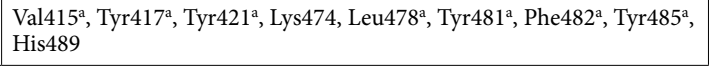 & 7 \\
\hline
\end{tabular}




\begin{tabular}{|c|c|c|c|c|}
\hline Peptide & Pepsite-2 p-value & Reactive peptide residues & Bound sites (3RQ7) & CBS \\
\hline GLHPVPQPLV & 0.0005692 & H3, P4, V5, P6, Q7, P8 & 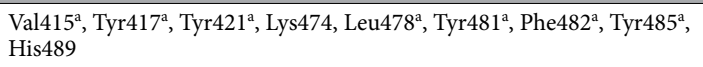 & 7 \\
\hline \multicolumn{5}{|c|}{ ( } \\
\hline LRPFL & 0.002388 & R2, P3, F4, L5 & 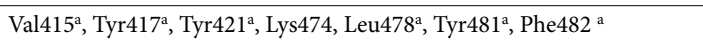 & 6 \\
\hline LRFPL & 0.001516 & R2, F3, P4, L5 & 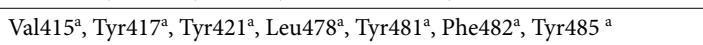 & 7 \\
\hline LC & 0.02921 & $\mathrm{~L} 1, \mathrm{C} 2$ & Tyr417 ${ }^{\mathrm{a}}$, Tyr421 ${ }^{\mathrm{a}}$, Lys474, Leu $478^{\mathrm{a}}$, Tyr $481^{\mathrm{a}}$, Phe $482^{\mathrm{a}}$ & 5 \\
\hline HSGF & 0.01477 & H1, S2, G3, F4 & 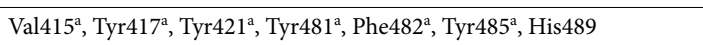 & 6 \\
\hline LWKL & 0.01982 & L1, W2, K3, L4 & 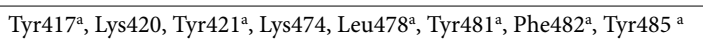 & 6 \\
\hline PLLL & 0.00254 & P1, L2, L3, L4 & 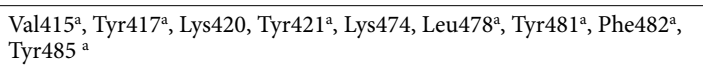 & 7 \\
\hline ESLPGVPPPSGQPLL & 0.007101 & L3, P4, G5, V6, P7, P8, P9, S10, Q12, P13, L14, L15 & $\begin{array}{l}\text { Val415a , Tyr417 }{ }^{\mathrm{a}} \text {, Lys } 420, \text { Tyr } 421^{\mathrm{a}} \text {, Lys } 474, \text { Leu } 478^{\mathrm{a}} \text {, Tyr } 481^{\mathrm{a}} \text {, Phe } 482^{\mathrm{a}} \text {, } \\
\text { Tyr485 a }\end{array}$ & 7 \\
\hline KPVMECGALLL & 0.004389 & K1, P2, V3, M4, C6, A8, L9, L10, L11 & $\begin{array}{l}\text { Val415a, Tyr } 417^{\mathrm{a}} \text {, Tyr } 421^{\mathrm{a}} \text {, Lys } 474, \text { Leu } 478^{\mathrm{a}}, \text { Tyr } 481^{\mathrm{a}} \text {, Phe } 482^{\mathrm{a}} \text {, Tyr } 485^{\mathrm{a}} \text {, } \\
\text { His } 489\end{array}$ & 7 \\
\hline CHLL & 0.0129 & $\mathrm{C} 1, \mathrm{H} 2, \mathrm{~L} 3, \mathrm{~L} 4$ & 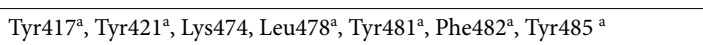 & 6 \\
\hline CFNTLMLPPEPLL & 0.001375 & $\mathrm{C} 1, \mathrm{~F} 2, \mathrm{~N} 3, \mathrm{~T} 4, \mathrm{M} 6, \mathrm{~L} 7, \mathrm{P} 8, \mathrm{P} 9, \mathrm{E} 10, \mathrm{P} 11, \mathrm{~L} 13$ & 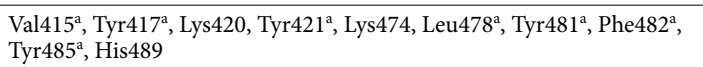 & 7 \\
\hline SHGM & 0.004702 & S1, H2, G3, M4 & 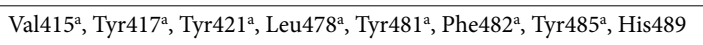 & 7 \\
\hline QVNLPLTGGML & 0.009459 & Q1, N3, L4, P5, L6, T1, G9, M10, L11 & 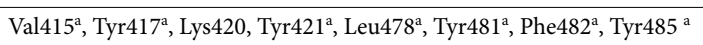 & 7 \\
\hline HSYAEEPPLYPLL & 0.01899 & H1, S2, Y3, A4, E6, P7, P8, L9, Y10, P11, L13 & 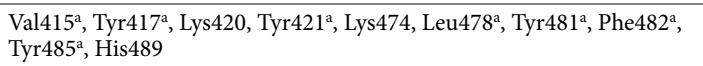 & 7 \\
\hline DLPLMT & 0.002004 & D1, L2, P3, L4, M5 & $\begin{array}{l}\text { Val415a, Tyr417 }{ }^{\mathrm{a}} \text {, Tyr421 }{ }^{\mathrm{a}} \text {, Lys474, Leu } 478^{\mathrm{a}} \text {, Tyr } 481^{\mathrm{a}} \text {, Phe } 482^{\mathrm{a}} \text {, Tyr } 485^{\mathrm{a}} \text {, } \\
\text { His489 }\end{array}$ & 7 \\
\hline NNLPLTM & 0.000809 & N2, L3, P4, L5, T6, M7 & 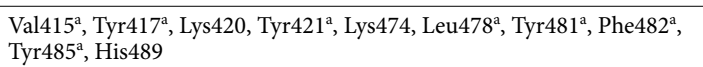 & 7 \\
\hline PLMLPLHQPL & 0.001916 & M3, L4, P5, L6, H7, Q8 & 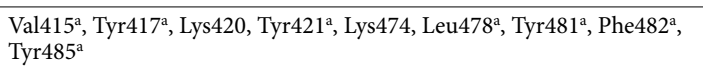 & 7 \\
\hline DLLPLTM & 0.001321 & L2, L3, P4, L5, T6, M7 & 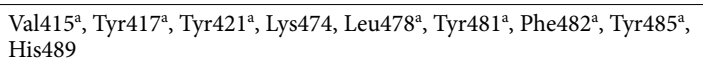 & 7 \\
\hline FLEL & 0.03925 & F1, L2, E3, L4 & 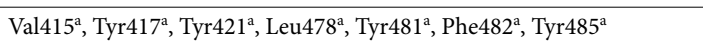 & 7 \\
\hline NHCDEPVPMT & 0.004474 & D4, P6, V7, P8, M9, T10 & 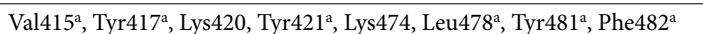 & 6 \\
\hline
\end{tabular}

Table 3. The Pepsite $2 \mathrm{p}$-values, reactive residues and potential binding sites of the selected peptides within the active site of PLK-1 Polo box domain (PDB-ID: 3RQ7). CBS no. of bound cryptic binding sites. ${ }^{\text {a Cryptic }}$ binding sites.

\begin{abstract}
Materials and methods
Preparation of camel whey proteins. Camel whey proteins were prepared from raw camel milk samples obtained from healthy camels (Camelus dromedaries) kept at a local camel farm located in Al Ain, Abu Dhabi, United Arab Emirates (UAE). Camel milk samples were immediately transferred under refrigerated conditions to Food Chemistry laboratory at College of Food and Agriculture, United Arab Emirates University. The milk samples were skimmed by centrifuging the samples at a speed of $4255 \times g$ for $15 \mathrm{~min}$ at $10{ }^{\circ} \mathrm{C}$ using a Allegra $\mathrm{X}-30 \mathrm{R}$ centrifuge (Beckhman coulter, Inc, California, USA) and the separated fat layer was removed manually using spatula and muslin cloth. The process was repeated twice to achieve maximum removal of milk fats. Whey separation was achieved by isoelectric precipitation of casein proteins by reducing the $\mathrm{pH}$ as described by Kamal, et al. ${ }^{9}$. The samples were stored at $4{ }^{\circ} \mathrm{C}$ for $12 \mathrm{~h}$ to enhance casein precipitation. Casein precipitates were separated using centrifugation at $10,000 \times g$ for $10 \mathrm{~min}$ at $4{ }^{\circ} \mathrm{C}$. Centrifugation was repeated three times to ensure efficient separation of casein from whey proteins. Protein content of the whey samples was determined using the Bicinchoninic acid method as previously described by Mudgil et al. ${ }^{38}$. Whey was stored at $-20{ }^{\circ} \mathrm{C}$ and freeze dried within 3 days of production using freeze dryer (Telstar, Spain). Lyophilized whey proteins were reconstituted into $150 \mathrm{ml}$ of double distilled water adjusted to a final protein concentration of $3 \%$.
\end{abstract}

Camel whey protein hydrolysates generated with pepsin. The enzymatic hydrolysis of camel whey proteins (CWPs) was performed using gastric enzyme pepsin at $\mathrm{pH} 2.0$ via a design of experiment (DOE) consisting of different process parameters (temperature, time and enzyme concentration). The DOE utilized CWP solution containing a protein concentration of $3 \%$ which was hydrolysed using pepsin at three temperatures of $30{ }^{\circ} \mathrm{C}, 37{ }^{\circ} \mathrm{C}$, and $45^{\circ} \mathrm{C}$; two hydrolysis time intervals of 120 and $360 \mathrm{~min}$ and three different enzyme concentrations $(0.5,1$ and $2 \%)$ in a water bath shaker (Clifton NE5-28D, Nickel-electro LTD, North Somerset, UK) yielding a total of 18 different camel whey protein hydrolysates (CWPHs) (P1.1-1.3 to P6.1-6.3) as presented in Table 1. All hydrolysates produced at different conditions were generated in three batches. The enzymatic reaction was terminated by placing the samples in boiling water for $10 \mathrm{~min}$ followed by immediate cooling in ice cold water. Samples were then centrifuged at $10,000 \times g, 15 \mathrm{~min}$ at $4{ }^{\circ} \mathrm{C}$, supernatants were collected, $\mathrm{pH}$ was adjusted to neutral and stored at $-20^{\circ} \mathrm{C}$ until later further analysis. The anti-cancer and anti-inflammatory activities were performed within two weeks of hydrolysis. 


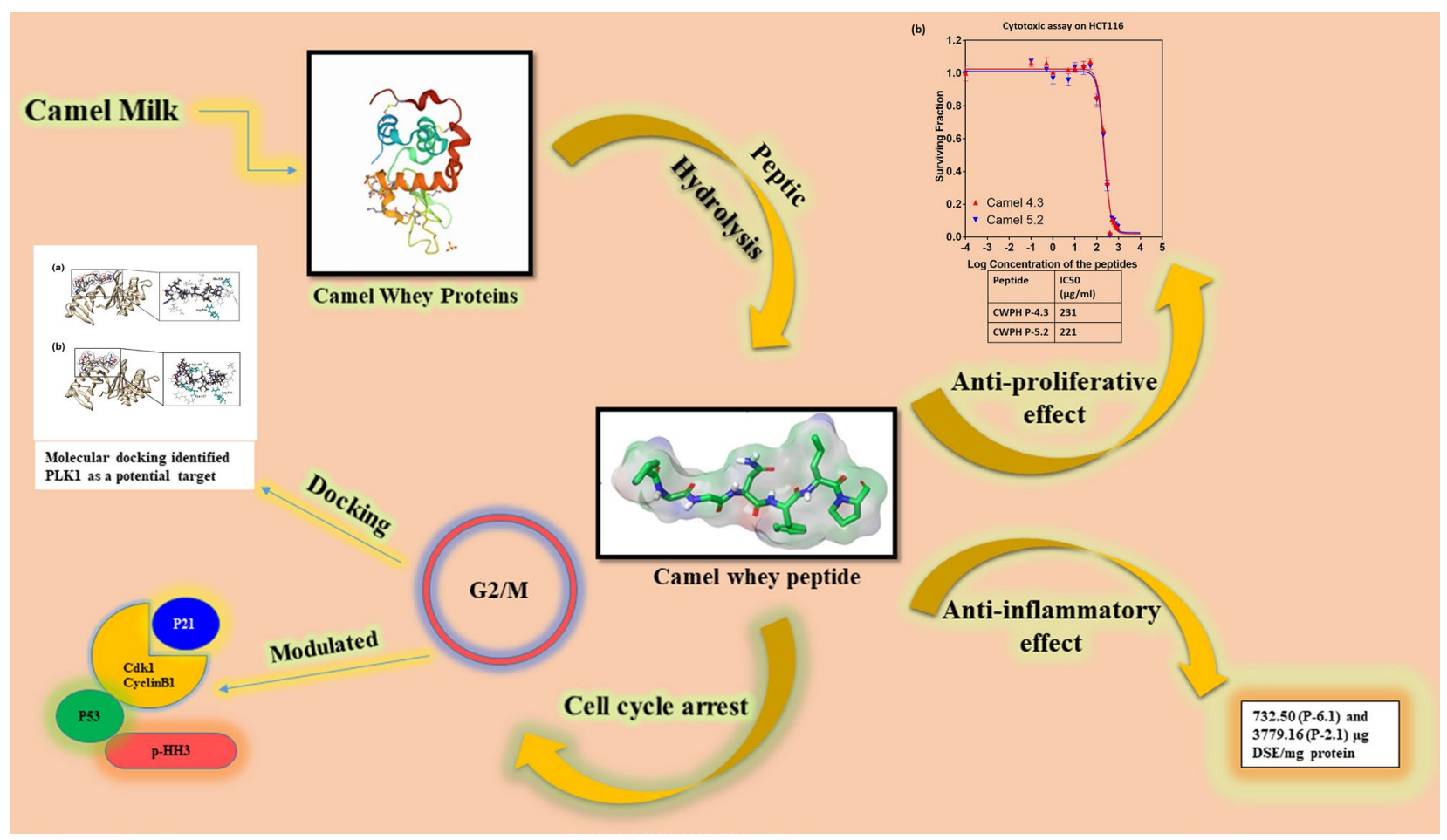

Figure 4. Camel whey protein hydrolysates induce G2/M cellcycle arrest in HCT116 cells. This graphical abstract shows the molecular mechanism employed by the camel whey protein hydrolysates in inducing antiproliferative effect on the human colorectal cancer cells implicating PLK1 as a potential target.

Characterization of camel milk protein hydrolysate (CMPHs). Degree of hydrolysis (\% DH). Degree of hydrolysis (DH) is defined as the proportion of cleaved peptide bonds in comparison to intact whey in a protein hydrolysate. It measures the free amino nitrogen (F-AN) using the O-phthalaldehyde (OPA) method of Church, et al. ${ }^{39}$. Briefly, fresh OPA reagent was prepared by mixing $25 \mathrm{ml}$ of sodium tetraborate buffer $(100 \mathrm{mM}$; $\mathrm{pH} 9.3), 2.5 \mathrm{ml}$ of sodium dodecyl sulphate $(20 \%, \mathrm{w} / \mathrm{w}), 40 \mathrm{mg}$ of OPA (dissolved in $1 \mathrm{ml}$ of methanol), and $100 \mu \mathrm{l}$ of $\beta$-mercaptoethanol. The total volume was then raised to $50 \mathrm{ml}$ using deionized water. A modified 96well microplate assay was used, where $25 \mu \mathrm{l}$ of samples were mixed with $300 \mu \mathrm{l}$ of the OPA reagent and absorbances were measured at $340 \mathrm{~nm}, 30 \mathrm{~min}$ after incubation at $37{ }^{\circ} \mathrm{C}$. Simultaneously, a standard curve of tryptone was prepared and the free amino content was calculated. DH values of hydrolysates obtained were calculated using Eq. (1) as described by Kleekayai et al. ${ }^{40}$

$$
D H(\%)=\frac{F-A N \text { hydrolysate }-F-A N \text { intact whey protein } \times 100}{N p b}
$$

$\mathrm{Npb}$ is the nitrogen content of the peptide bonds in whey protein $(123.3 \mathrm{mg} / \mathrm{g})^{40}$.

Peptide profile by reverse phase-ultra performance liquid chromatography (RP-UPLC). Reverse phase-ultra performance liquid chromatography (RP-UPLC) was utilized to monitor the peptide profile of the selected peptic camel whey protein hydrolysates ${ }^{41}$ with some modifications. Please refer to Supplementary material (S1) for details of the methodology.

Anti-inflammatory activity assay. The anti-inflammatory activity, as indicated by the protection of thermal denaturation of albumin protein, was determined according to the method described by Aguilar-Toalá et al. ${ }^{18}$ and modified by Kamal et al. ${ }^{9}$. Please refer to Supplementary material (S3) for details of the methodology.

Cell culture. The human liver cancer cell line, HepG2, was obtained frozen in liquid nitrogen from American Type Culture Collection (ATCC) and the human colon carcinoma cell line, HCT116, was obtained frozen from CLS Cell Lines Service GmbH. Both cells were cultured in defined RPMI 1640 medium (Gibco), supplemented with $10 \%$ fetal bovine serum (Sigma Aldrich) and containing $1 \%$ of $100 \mathrm{U} / \mathrm{ml}$ penicillin and $100 \mu \mathrm{g} /$ $\mathrm{ml}$ streptomycin (Sigma Aldrich) at $37^{\circ} \mathrm{C}$ in a humidified $5 \% \mathrm{CO}_{2}$ atmosphere. Cells were sub-cultured each 3-5 days using trypsin $0.25 \%$ (Hyclone).

Anti-proliferative assay. Effect of selected CWPHs (P-4.3 and P-5.2) on the proliferation of HCT116 cells was assessed using sulforhodamine-B (SRB) assay ${ }^{42}$. Cells were seeded in 96-well plates at a density of 8000 cells/ 
well for $24 \mathrm{~h}$ and then treated with different concentrations of peptides. After $48 \mathrm{~h}$ incubation, cells were fixed with ice-cold $50 \%$ trichloroacetic acid, stained with $0.4 \% \mathrm{SRB}$ and dissolved with $10 \mathrm{mM}$ Tris base solution. Absorbance was taken at $564 \mathrm{~nm}$ using a microplate reader (Thermo scientific, USA). The IC50 was calculated using Graphpad prism.

Cell cycle analysis. Cell cycle analysis was done using fluorescence-activated cell sorting (FACS) technique ${ }^{42}$. Cells were plated $\left(5 \times 10^{6}\right)$ in $75 \mathrm{~cm}^{2}$ culture flasks. After $24 \mathrm{~h}$, they were treated with CWPHs P-4.3 $(231 \mu \mathrm{g} / \mathrm{ml})$, incubated over a period of $24 \mathrm{~h}, 48 \mathrm{~h}$ and $72 \mathrm{~h}$ at $37^{\circ} \mathrm{C}$. After the incubation, cells were collected, fixed in $70 \%$ ethanol, treated with RNAse and stained with propidium iodide $(1 \mathrm{mg} / \mathrm{ml})$. DNA content was measured in FACScan flow cytometry (Becton Dickenson, San Jose, CA, USA) and data analysis were performed with FlowJo V.10 software (Tree Star, Inc, Ashland, OR, USA).

Western blotting. Western blot analysis was performed as described previously ${ }^{30}$. Briefly, cells were treated with CWPHs (P-4.3, $231 \mu \mathrm{g} / \mathrm{ml}$ ), incubated over a period of $24 \mathrm{~h}, 48 \mathrm{~h}$ and $72 \mathrm{~h}$. The primary antibodies used were p53, p21, CDK1, p-CDK1 (Tyr 15), Cyclin B1, p-histoneH3 and GAPDH (Cell Signalling Technology). Further blots were treated with horseradish peroxidase-conjugated antibody. Protein bands were detected using WesternSure Chemiluminescent Substrate (LI-COR) and captured by a Versadoc imager system (Biorad, USA). Quantification of the proteins was performed using the ImageJ software with GAPDH as the internal control.

Identification of peptides by liquid chromatography quadrupole time-of-flight tandem mass spectrometry (LC OTOF MS/MS). CWPHs P-4.3 and P-5.2 were selected for peptide sequencing and identification ascribed to their potential anti-cancer activity against human liver cancer cell line (HepG2) (Supplementary Fig. S1). Peptide sequencing was conducted using liquid chromatography quadrupole time-of-flight tandem mass spectrometry (LC QTOF MS/MS, Agilent 6520) according to the protocol as described by Sarah et al. ${ }^{43}$. Please refer to supplementary material (S2) for details of the methodology.

Physio-chemical properties of identified peptides and their in-silico structural activity relationship (SAR) within the active site of PLK-1 Polo box domain (PDB-ID: 3RQ7). The list of peptides obtained were subsequently screened using Peptide Ranker web server available at http://distilldeep.ucd.ie/ PeptideRanker/. Peptides with the score of above 0.50 were designated as potentially bioactive peptides (BAP) and subjected to a novelty check using a database search software (i.e. BIOPEP, PeptideDB, SwePep and EROPMoscow). The MW, isoelectric point and net charge at $\mathrm{pH} 7$ were calculated using a web utility called PepCalc (https://pepcalc.com/). Additionally, in silico prediction of the identified peptides, for their toxicity was done using the tool ToxinPred (https://webs.iiitd.edu.in/raghava/toxinpred/index.html), anti-inflammatory potential was checked using a sequence based prediction tool AIPpred (http://thegleelab.org/AIPpred/index.html) and anti-cancer potential was predicted using the ANTICP server (https://webs.iiitd.edu.in/raghava/anticp/index. html).

A web based program PepSite2 (http://pepsite2.russelllab.org/) was used to predict binding of a given peptide onto a protein structure (RCSB Protein Data Bank) to study the detailed interaction.

Molecular docking. Molecular docking of selected peptides showing peptide ranker score of $>0.8$ (AHLEQVLLR and ALPNIDPPTVER) was conducted against possible target protein obtained from the RSCB protein data bank (http://www.rcsb.org) using the MDockPeP server. Additionally, target prediction studies were carried-out using SwissTargetPrediction (http://www.swisstargetprediction.ch/), MolTarPred (http://moltarpred. marseille.inserm.fr/), SEA (http://sea.bkslab.org/) and PASS (http://www.pharmaexpert.ru/passonline/index. php) online search engines. The model with the highest ITScorePeP was considered for further analysis. The accuracy of the binding mode was assessed based on location of the original bound ligand. The 3D-best docked poses and interactions were visualized using PyMOL molecular viewer (Schrödinger Inc., New York, NY, USA).

Statistical analysis. All the pepsin derived CWPHs were produced in three batches and degree of hydrolysis and anti-inflammatory activities were performed in triplicate and the data were subjected to Analysis of Variance (ANOVA) and appropriate means separation was conducted using Tukey's multiple range test using a statistical software program (SPSS version 21 for Windows, 2012, Chicago, IL, USA). For anticancer activities, results are expressed as the mean \pm SEM of at least three independent experiments and statistical analyses were performed using the Student's t-test.

Received: 30 November 2020; Accepted: 1 March 2021

Published online: 29 March 2021

\section{References}

1. Nongonierma, A. B. et al. Dipeptidyl peptidase IV (DPP-IV) inhibitory properties of a camel whey protein enriched hydrolysate preparation. Food Chem. 279, 70-79 (2019).

2. Chalamaiah, M., Yu, W. \& Wu, J. Immunomodulatory and anticancer protein hydrolysates (peptides) from food proteins: A review. Food Chem. 245, 205-222 (2018). 
3. Hernandez-Ledesma, B., Hsieh, C. C. \& de Lumen, B. O. Antioxidant and anti-inflammatory properties of cancer preventive peptide lunasin in RAW 264.7 macrophages. Biochem. Biophys. Res. Commun. 390, 803-808. https://doi.org/10.1016/j.bbrc.2009. $10.053(2009)$

4. Daliri, E. B., Oh, D. H. \& Lee, B. H. Bioactive peptides. Foods. https://doi.org/10.3390/foods6050032 (2017).

5. Wang, L., Dong, C., Li, X., Han, W. \& Su, X. Anticancer potential of bioactive peptides from animal sources. Oncol. Rep. 38, 637-651. https://doi.org/10.3892/or.2017.5778 (2017).

6. Wernery, U. Camel milk, the white gold of the desert. J. Camel Practice Res. 13, 15 (2006).

7. Gader, A. G. M. A. \& Alhaider, A. A. The unique medicinal properties of camel products: A review of the scientific evidence. J. Taibah Univ. Med. Sci. 11, 98-103. https://doi.org/10.1016/j.jtumed.2015.12.007 (2016).

8. Habib, H. M., Ibrahim, W. H., Schneider-Stock, R. \& Hassan, H. M. Camel milk lactoferrin reduces the proliferation of colorectal cancer cells and exerts antioxidant and DNA damage inhibitory activities. Food Chem. 141, 148-152 (2013).

9. Kamal, H. et al. Inhibitory properties of camel whey protein hydrolysates toward liver cancer cells, dipeptidyl peptidase-IV, and inflammation. J. Dairy Sci. 101, 1-10 (2018).

10. Villegas, I., Sanchez-Fidalgo, S. \& de la Lastra, C. A. New mechanisms and therapeutic potential of curcumin for colorectal cancer. Mol. Nutr. Food Res. 52, 1040-1061. https://doi.org/10.1002/mnfr.200700280 (2008).

11. Ambigaipalan, P. \& Shahidi, F. Date seed flour and hydrolysates affect physicochemical properties of muffin. Food Biosci. 12, 54-60 (2015)

12. Jafar, S., Kamal, H., Mudgil, P., Hassan, H. M. \& Maqsood, S. Camel whey protein hydrolysates displayed enhanced cholesteryl esterase and lipase inhibitory, anti-hypertensive and anti-haemolytic properties. LWT-Food Sci. Technol. 98, 212-218 (2018).

13. Tagliazucchi, D., Shamsia, S. \& Conte, A. Release of angiotensin converting enzyme-inhibitory peptides during in vitro gastrointestinal digestion of camel milk. Int. Dairy J. 56, 119-128 (2016).

14. Salami, M. et al. Enzymatic digestion and antioxidant activity of the native and molten globule states of camel $\alpha$-lactalbumin: Possible significance for use in infant formula. Int. Dairy J. 19, 518-523 (2009).

15. Nongonierma, A. B. \& FitzGerald, R. J. Features of dipeptidyl peptidase IV (DPP-IV) inhibitory peptides from dietary proteins. J. Food Biochem. 43, e12451. https://doi.org/10.1111/jfbc.12451 (2019).

16. Guha, S. \& Majumder, K. Structural-features of food-derived bioactive peptides with anti-inflammatory activity: A brief review. J. Food Biochem. 43, e12531 (2019).

17. Ebaid, H., Ahmed, O. M., Mahmoud, A. M. \& Ahmed, R. R. Limiting prolonged inflammation during proliferation and remodeling phases of wound healing in streptozotocin-induced diabetic rats supplemented with camel undenatured whey protein. $B M C$ Immunol. 14, 31 (2013).

18. Aguilar-Toalá, J. et al. Assessment of multifunctional activity of bioactive peptides derived from fermented milk by specific Lactobacillus plantarum strains. J. Dairy Sci. 100, 65-75 (2017).

19. Marcone, S., Haughton, K., Simpson, P. J., Belton, O. \& Fitzgerald, D. J. Milk-derived bioactive peptides inhibit human endothelialmonocyte interactions via PPAR- $\gamma$ dependent regulation of NF- $\mathrm{\kappa B}$. J. Inflamm. 12, 1 (2015).

20. Liang, Q., Chalamaiah, M., Ren, X., Ma, H. \& Wu, J. Identification of new anti-inflammatory peptides from zein hydrolysate after simulated gastrointestinal digestion and transport in caco-2 cells. J. Agric. Food Chem. 66, 1114-1120 (2018).

21. Damiens, E. et al. Lactoferrin inhibits G1 cyclin-dependent kinases during growth arrest of human breast carcinoma cells. J. Cell. Biochem. 74, 486-498 (1999).

22. Krishnankutty, R. et al. Anticancer activity of camel milk via induction of autophagic death in human colorectal and breast cancer cells. Asian Pacif. J. Cancer Prevent. APJCP 19, 3501-3509. https://doi.org/10.31557/APJCP.2018.19.12.3501 (2018).

23. Korashy, H. M., Maayah, Z. H., Abd-Allah, A. R., El-Kadi, A. O. \& Alhaider, A. A. Camel milk triggers apoptotic signaling pathways in human hepatoma HepG2 and breast cancer MCF7 cell lines through transcriptional mechanism. J. Biomed. Biotechnol. 2012, 9. https://doi.org/10.1155/2012/593195 (2012).

24. De Simone, C. et al. Peptides from water buffalo cheese whey induced senescence cell death via ceramide secretion in human colon adenocarcinoma cell line. Mol. Nutr. Food Res. 55, 229-238. https://doi.org/10.1002/mnfr.201000074 (2011).

25. Gavet, O. \& Pines, J. Progressive activation of CyclinB1-Cdk1 coordinates entry to mitosis. Dev. Cell 18, 533-543. https://doi.org/ 10.1016/j.devcel.2010.02.013 (2010).

26. Schmidt, M. et al. Regulation of G2/M transition by inhibition of WEE1 and PKMYT1 kinases. Molecules https://doi.org/10.3390/ molecules22122045 (2017).

27. Park, C. H. \& Kim, K. T. Apoptotic phosphorylation of histone H3 on Ser-10 by protein kinase Cdelta. PLoS ONE 7, e44307. https:// doi.org/10.1371/journal.pone.0044307 (2012).

28. Nowak, S. J. \& Corces, V. G. Phosphorylation of histone H3: A balancing act between chromosome condensation and transcriptional activation. Trends Genet. 20, 214-220. https://doi.org/10.1016/j.tig.2004.02.007 (2004).

29. Abbas, T. \& Dutta, A. p21 in cancer: Intricate networks and multiple activities. Nat. Rev. Cancer 9, 400-414. https://doi.org/10. $1038 / \mathrm{nrc} 2657$ (2009).

30. Al-Hrout, A. et al. Safranal induces DNA double-strand breakage and ER-stress-mediated cell death in hepatocellular carcinoma cells. Sci. Rep. 8, 16951. https://doi.org/10.1038/s41598-018-34855-0 (2018).

31. Li, D., Tian, Y., Ma, Y. \& Benjamin, T. p150(Sal2) is a p53-independent regulator of p21(WAF1/CIP). Mol. Cell Biol. 24, 3885-3893. https://doi.org/10.1128/mcb.24.9.3885-3893.2004 (2004).

32. Sowmya, K., Bhat, M. I., Bajaj, R. K., Kapila, S. \& Kapila, R. Buffalo milk casein derived decapeptide (YQEPVLGPVR) having bifunctional anti-inflammatory and antioxidative features under cellular milieu. Int. J. Pept. Res. Ther. 25, 623-633 (2019).

33. Juillerat-Jeanneret, L., Robert, M. C. \& Juillerat, M. A. Peptides from Lactobacillus hydrolysates of bovine milk caseins inhibit prolyl-peptidases of human colon cells. J. Agric. Food Chem. 59, 370-377. https://doi.org/10.1021/jf102803a (2011).

34. Toyoshima-Morimoto, F., Taniguchi, E., Shinya, N., Iwamatsu, A. \& Nishida, E. Polo-like kinase 1 phosphorylates cyclin B1 and targets it to the nucleus during prophase. Nature 410, 215-220. https://doi.org/10.1038/35065617 (2001).

35. Lowery, D. M., Lim, D. \& Yaffe, M. B. Structure and function of Polo-like kinases. Oncogene 24, 248-259. https://doi.org/10.1038/ sj.onc.1208280 (2005).

36. Strebhardt, K. \& Ullrich, A. Targeting polo-like kinase 1 for cancer therapy. Nat. Rev. Cancer 6, 321-330 (2006).

37. Zhao, X. Z., Hymel, D. \& Burke, T. R. Jr. Enhancing polo-like kinase 1 selectivity of polo-box domain-binding peptides. Bioorg. Med. Chem. 25, 5041-5049 (2017)

38. Mudgil, P. et al. Molecular binding mechanism and identification of novel antihypertensive peptides from camel milk protein hydrolysates. $L W T$ https://doi.org/10.1016/j.lwt.2019.05.091 (2019).

39. Church, F. C., Swaisgood, H. E., Porter, D. H. \& Catignani, G. L. Spectrophotometric assay using o-phthaldialdehyde for determination of proteolysis in milk and isolated milk proteins1. J. Dairy Sci. 66, 1219-1227 (1983).

40. Kleekayai, T., Le Gouic, A. V., Deracinois, B., Cudennec, B. \& FitzGerald, R. J. In vitro characterisation of the antioxidative properties of whey protein hydrolysates generated under $\mathrm{pH}$ - and non $\mathrm{pH}$-controlled conditions. Foods 9 , 582. https://doi.org/10.3390/ foods $9050582(2020)$.

41. Nongonierma, A. B. \& Fitzgerald, R. J. Tryptophan-containing milk protein-derived dipeptides inhibit xanthine oxidase. Peptides 37, 263-272. https://doi.org/10.1016/j.peptides.2012.07.030 (2012).

42. El-Awady, R. A., Saleh, E. M., Ezz, M. \& Elsayed, A. M. Interaction of celecoxib with different anti-cancer drugs is antagonistic in breast but not in other cancer cells. Toxicol. Appl. Pharmacol. 255, 271-286. https://doi.org/10.1016/j.taap.2011.06.019 (2011). 
43. Sarah, S. et al. LC-QTOF-MS identification of porcine-specific peptide in heat treated pork identifies candidate markers for meat species determination. Food Chem. 199, 157-164 (2016).

\section{Acknowledgements}

Authors would like to acknowledge financial support for this study from Terry Fox foundation Grant (Fund code: 21F044-Terry Fox) and UPAR Grant (31F094) funded by UAE University for Sajid Maqsood, and by ZCHS fund \# 31R174 for Amr Amin. Also, Dr. Hassan, M. Hassan is acknowledged for RP-UPLC analysis.

\section{Author contributions}

C.M.: methodology, formal analysis, data curation, writing-original draft, P.M.: methodology, formal analysis, data curation, writing - review and editing, G.C.Y.: formal analysis, data curation, writing-review and editing, H.T.: software, validation, writing-review \& editing, R.E.-A.: formal analysis, investigation resources, data, writing - review and editing, supervision, Y.A.: data analysis, data curation, writing — original draft, writingreview and editing, A.A.: conceptualization, investigation resources, writing-original draft, review and editing, visualization, project administration funding acquisition, S.M.: conceptualization, investigation resources, writing - review and editing, visualization, supervision, project administration and funding acquisition.

\section{Competing interests}

The authors declare no competing interests.

\section{Additional information}

Supplementary Information The online version contains supplementary material available at https:/doi.org/ 10.1038/s41598-021-86391-z.

Correspondence and requests for materials should be addressed to A.A. or S.M.

Reprints and permissions information is available at www.nature.com/reprints.

Publisher's note Springer Nature remains neutral with regard to jurisdictional claims in published maps and institutional affiliations.

(c) (i) Open Access This article is licensed under a Creative Commons Attribution 4.0 International License, which permits use, sharing, adaptation, distribution and reproduction in any medium or format, as long as you give appropriate credit to the original author(s) and the source, provide a link to the Creative Commons licence, and indicate if changes were made. The images or other third party material in this article are included in the article's Creative Commons licence, unless indicated otherwise in a credit line to the material. If material is not included in the article's Creative Commons licence and your intended use is not permitted by statutory regulation or exceeds the permitted use, you will need to obtain permission directly from the copyright holder. To view a copy of this licence, visit http://creativecommons.org/licenses/by/4.0/.

(C) The Author(s) 2021 